Check for updates

Cite this: New J. Chem., 2017, 41, 11647

Received 6th June 2017

Accepted 20th August 2017

DOI: 10.1039/c7nj02013a

rsc.li/njc

\section{Control of structure, stability and catechol oxidase activity of copper(II) complexes by the denticity of tripodal platforms $\dagger$}

\begin{abstract}
Ferenc Matyuska, ${ }^{a}$ Nóra V. May, ${ }^{b}$ Attila Bényei ${ }^{\mathrm{c}}$ and Tamás Gajda (D) *a
Copper(II) complexes of a new polydentate tripodal ligand trenpyz (L, tris[2-(5-pyrazolylmethyl)aminoethyl]amine) were characterized in both solution and solid states. A combined evaluation of potentiometric UV-Vis and EPR data provided both thermodynamic and structural information on the complexes formed in solution. In equimolar solution the highly stable square pyramidal $\mathrm{CuHL}$ and trigonal bipyramidal $\mathrm{CuL}$ are the dominant species at around $\mathrm{pH} 3$ and 5-8, respectively. Above $\mathrm{pH} 8$ further deprotonation was observed ( $\mathrm{pK}=9.56$ ), which is related to the formation of a copper(I)-bound pyrazolate anion. This creates the possibility for the formation of oligonuclear complexes, through pyrazolate bridges, and at a 3/2 Cu(II)/L ratio three trinuclear complexes were identified, similar to the copper(I)-tachpyz $\left(N, N^{\prime}, N^{\prime \prime}-\operatorname{tris}(5\right.$ pyrazolylmethyl)-1,3,5-cis,cis-triamino-cyclohexane) system studied earlier. The trinuclear complexes of the two ligands have considerably different speciations, due to the different denticities of tripodal platforms. At the optimal pH the catechol oxidase activities of the triply deprotonated trinuclear complexes of trenpyz and tachpyz are similar, but the $\mathrm{pH}$-rate constant profiles are significantly different, as a consequence of the deviations in their speciation. Consequently, the $\mathrm{H}_{2} \mathrm{dtbc}$ oxidation promoted by these trinuclear complexes can be easily controlled by the denticity of the tripodal ligands, since it affects the coordination environment of the central metal ion, which is proposed to be the main actor during the reaction.
\end{abstract}

\section{Introduction}

In order to develop tailor made metal ion chelators as well as efficient low molecular weight enzyme mimics, the favourable spatial distribution of donor atoms in tripodal ligands is frequently exploited. ${ }^{1-15}$ The derivatization of simple tripodal platforms, such as cis,cis-1,3,5-triaminocyclohexane (tach) and tris-(2-aminoethyl)amine (tren), provides additional donor site(s) to increase the thermodynamic stability of their metal complexes, ${ }^{4-8}$ or introduces further metal binding site(s) to create oligonuclear complexes. ${ }^{9-13}$

Tachpyr ( $N, N^{\prime}, N^{\prime \prime}$-tris(2-pyridylmethyl)-cis,cis-1,3,5-triaminocyclohexane) and trenpyr (tris[2-(2-pyridylmethyl)aminoethyl]amine) are two well-known and versatile polydentate tripodal ligands. ${ }^{4-8}$ The manganese(II) complex of trenpyr is a highly active

\footnotetext{
${ }^{a}$ Department of Inorganic and Analytical Chemistry, University of Szeged, Dóm tér 7, H-6720 Szeged, Hungary. E-mail: gajda@chem.u-szeged.hu

${ }^{b}$ Research Centre for Natural Sciences HAS, Magyar tudósok körútja 2, H-1117 Budapest, Hungary

${ }^{c}$ Department of Pharmaceutical Chemistry, University of Debrecen, Egyetem tér 1, Debrecen H-4032, Hungary

$\dagger$ Electronic supplementary information (ESI) available. CCDC 1553801 and 1553857. For ESI and crystallographic data in CIF or other electronic format see DOI: 10.1039/c7nj02013a
}

SOD-mimicking compound. ${ }^{4}$ Tachpyr and some of its derivatives are promising chelators of ${ }^{64 / 67} \mathrm{Cu}$ for radiotherapeutic uses ${ }^{5}$ and cytotoxic metal chelators with potential anti-tumor activity. ${ }^{6}$

Due to the favourable position of pyridine nitrogen atoms of tachpyr and trenpyr, these ligands embrace the metal ions by fused chelate rings. Therefore, their metal ion complexes have outstanding thermodynamic stability, although the coordination geometries are different for the two ligands. ${ }^{7-9}$ As a consequence of their encapsulating effect, these ligands rarely form oligonuclear complexes. Nevertheless, the heptadentate nature of trenpyr, and the analogous imidazole derivatives, allows the formation of tricopper(II) complexes, with rather long metal-metal separation. ${ }^{9,10}$ On the other hand, the bridging coordination of phenolate oxygens of tris(2-hydroxybenzylamino-ethyl)amine and its derivatives provide the formation of ferromagnetically coupled di-, tri- and tetranuclear cores with short metal-metal separations. ${ }^{11,12}$

In order to retain the encapsulating properties and to introduce an oligonucleating feature with short metal-metal distances, promoting in this way the cooperation of metal centres for enzyme mimicry, pyrazole-substitution seems to be well suited too. ${ }^{13}$ Pyrazolate-bridged metal complexes have received significant attention over recent decades, ${ }^{\mathbf{1 4 , 1 5}}$ and such centres may efficiently mimic the function of both hydrolase ${ }^{16}$ and oxidoreductase enzymes. ${ }^{17,18}$ 



trenpyz (L)

\section{tachpyz}

Scheme 1 Schematic structure of the ligand trenpyz (L) studied in this work, and a related ligand studied earlier. ${ }^{13}$

Recently, we prepared tachpyz $\left(N, N^{\prime}, N^{\prime \prime}\right.$-tris(5-pyrazolylmethyl)1,3,5-cis,cis-triamino-cyclohexane, Scheme 1), a new tripodal ligand, ${ }^{13}$ which forms a highly stable mononuclear complex. Nevertheless it readily transforms into a unique trinuclear species that features a tetra(pyrazolate)-bridged linear tricopper(II) core. According to the crystal structure determined for $\left[\mathrm{Cu}_{3} \mathrm{H}_{-4}(\text { tachpyz })_{2}\right]$ $\left(\mathrm{ClO}_{4}\right)_{2} \cdot 5 \mathrm{H}_{2} \mathrm{O}$, the two peripheral metal ions have square pyramidal geometry, and the central copper(II) has tetrahedral geometry. ${ }^{13}$ The triply deprotonated trinuclear complex $\left(\mathrm{Cu}_{3} \mathrm{H}_{-3}(\operatorname{tachpyz})_{2}\right)$ is an efficient catechol oxidase mimic, which shows a surprisingly low $\mathrm{pH}$ optimum at $\mathrm{pH}=5.6$.

In order to explore the role of tripodal platforms in the stability, structure and enzyme mimicry, we designed a new tripodal ligand (tris[2-(5-pyrazolylmethyl)aminoethyl]amine, trenpyz, Scheme 1), which is a tren-based variant of tachpyz. Here, we report the synthesis and crystal structure of trenpyz, as well as the study of its copper(II) complexes both in solution and in the solid state. To screen the enzyme mimetic properties of the copper(II)-trenpyz complexes, and to compare to those of tachpyr, ${ }^{13}$ we also investigated their catechol oxidase activity by using 3,5-di-tert-butylcatechol $\left(\mathrm{H}_{2} \mathrm{dtbc}\right)$ as the model substrate.

\section{Experimental}

\section{Materials}

A copper(II) perchlorate solution was prepared from analytically pure compounds obtained from Sigma-Aldrich and standardized complexometrically. A 0.1 M NaOH standard solution (Sigma) was used for $\mathrm{pH}$ titration. The compounds tris-(2-aminoethyl)amine (tren, Sigma-Aldrich) and $1 \mathrm{H}$-pyrazole-5-carboxaldehyde (Novochemy Ltd), $N$-(2-hydroxyethyl)piperazine- $N$-ethanesulfonic acid (HEPES, Sigma-Aldrich), 2-(cyclohexylamino)-ethanesulfonic acid (CHES, Sigma-Aldrich), 3,5-ditertbuthylcatechol ( $\mathrm{H}_{2} \mathrm{dtbc}$, Alfa Aesar), 4-nitrocatechol $\left(\mathrm{H}_{2} 4 \mathrm{nc}\right.$, Sigma-Aldrich), dichloromethane (Molar Chemicals), acetonitrile (VWR) and trifluoracetic acid (TFA, Sigma-Aldrich) were analytically pure chemicals and used without further purification.

\section{Synthesis of tris[2-(5-pyrazolylmethyl)aminoethyl]amine (trenpyz, L)}

$0.349 \mathrm{~g}$ of tren $(2.38 \mathrm{mmol})$ and $0.755 \mathrm{~g}$ of $1 H$-pyrazole-5carboxaldehyde $(7.85 \mathrm{mmol})$ were mixed in $50 \mathrm{ml}$ of water-free methanol using 3 Å molecular sieves, and refluxed for $4 \mathrm{~h}$. After cooling $1.0 \mathrm{~g}(26.6 \mathrm{mmol})$ of $\mathrm{NaBH}_{4}$ was added to the solution in small portions and stirred overnight. Then the methanol was evaporated, the crude product was dissolved in ethanol, and the $\mathrm{pH}$ was set to $\sim 2$ with concentrated aqueous $\mathrm{HCl}$. The precipitate formed under these conditions contained the remaining boric acid derivatives. After filtering, the filtrate was treated with dry $\mathrm{HCl}$ gas, which resulted in the precipitation of the crude product, as trenpyz. $6 \mathrm{HCl}$. In some cases further purification was performed by preparative HPLC (reverse phase column, Supelco C18, $25 \mathrm{~cm} \times 10 \mathrm{~mm}$ geometry, $5 \mu \mathrm{m}$ pore diameter, gradient elution mode, $3 \mathrm{ml} \mathrm{min}{ }^{-1}$ flow rate, $t_{\mathrm{r}}{ }^{\prime}=18 \mathrm{~min}$ ), which, after lyophilization, yielded the TFA-salt of the ligand. The product was identified using LC-ESI-MS (Finnigan TSQ-7000) $\mathrm{m} / \mathrm{z}$ calculated for [C18H31N10] ${ }^{+} 387.2733$, found 387.2726 and ${ }^{1} \mathrm{H}-\mathrm{NMR}$ $\left(\mathrm{H}_{2} \mathrm{O}-\mathrm{D}_{2} \mathrm{O}\right.$ 90/10 solvent, Bruker Avance DRX 500): 7.68, d, 3H; 6.42 , d, $3 \mathrm{H} ; 4.21$, s $6 \mathrm{H} ; 3.06, \mathrm{t}, 6 \mathrm{H} ; 2.75 \mathrm{t}, 6 \mathrm{H}$, no other signals were detected. Elemental analysis (\%): for $\mathrm{C}_{18} \mathrm{H}_{36} \mathrm{~N}_{10} \mathrm{Cl}_{6} \cdot 2 \mathrm{H}_{2} \mathrm{O}$ calcd: C 33.71, H 6.24, N 21.85; found: C 33.7, H 5.8, N 21.8. Melting point: 253-258 ${ }^{\circ} \mathrm{C}$ (decomposition). IR (KBr): $\nu=3345(\mathrm{~m})$, 2950 (w), 2630 (s), 1457 (s), 1439 (s), 1400 (m), 1339 (w), 1281 (m), 1232 (m), $1215(\mathrm{w}), 1193(\mathrm{w}), 1155$ (w), 1123 (w), 1105 (m), 1079 (w), 1048 (m), $1010(\mathrm{w}), 995(\mathrm{~m}), 874(\mathrm{~m}), 784(\mathrm{~s}), 735(\mathrm{w})$, $677(\mathrm{w}), 616(\mathrm{~m}), 418(\mathrm{w}) \mathrm{cm}^{-1}$. UV (in $\mathrm{H}_{2} \mathrm{O}$ ): shoulders at 290 $\left(\varepsilon=2200 \mathrm{M}^{-1} \mathrm{~cm}^{-1}\right)$ and $230 \mathrm{~nm}\left(\varepsilon=6000 \mathrm{M}^{-1} \mathrm{~cm}^{-1}\right)$.

\section{$\mathrm{X}$-ray data collection, structure solution and refinement}

Crystals suitable for X-ray diffraction were obtained upon slow evaporation at room temperature from an ethanolic solution (trenpyz $\cdot 3 \mathrm{HCl} \cdot 2 \mathrm{H}_{2} \mathrm{O}$ ) and from aqueous solution at $\mathrm{pH}=8.2$ containing $\mathrm{Cu}\left(\mathrm{ClO}_{4}\right)_{2}$ and trenpyz in a $1: 1$ concentration ratio (compound 1). The data collection on the free ligand trenpyz$3 \mathrm{HCl} \cdot 2 \mathrm{H}_{2} \mathrm{O}$ was performed at $25{ }^{\circ} \mathrm{C}$ on a Bruker-Nonius MACH3 diffractometer using $\mathrm{Mo} \mathrm{K} \alpha$ radiation, and semi-empirical absorption collection was performed by collecting psi-scan data. The blue single crystal of $\mathbf{1}$ was mounted on a loop and transferred to the goniometer. X-ray diffraction data were collected at $-170{ }^{\circ} \mathrm{C}$ on a Rigaku RAXIS-RAPID II diffractometer using also Mo $\mathrm{K} \alpha$ radiation. A numerical absorption correction ${ }^{19}$ was carried out using the program CrystalClear. ${ }^{20}$ Sir $2014^{21}$ and SHELXL ${ }^{22}$ under WinGX $^{23}$ software were used for solution and refinement, respectively. The model was refined by full-matrix least squares on $F^{2}$. A summary of data collection parameters is given in Table 1 . In the structure, hydrogen atom positions were located in difference electron density maps and placed into geometric positions. They were included in structure factor calculations but they were not refined except the water protons in the structure of trenpyz $3 \mathrm{HCl} \cdot 2 \mathrm{H}_{2} \mathrm{O}$, where the $\mathrm{O}-\mathrm{H}$ distances were restrained. These hydrogen atoms were shifting significantly between two orientations of the water molecules; however this not affected by the correctness of the structure determination significantly.

The isotropic displacement parameters of the hydrogen atoms were approximated from the $U(\mathrm{eq})$ value of the atom they were bonded to. Refinement of non-hydrogen atoms was carried out with anisotropic temperature factors except for the disordered oxygens of one of the perchlorate anions. Selected bond lengths and angles of 
Table 1 Crystal data and structure refinement for trenpyz.3 $3 \mathrm{HCl} \cdot 2 \mathrm{H}_{2} \mathrm{O}$ and $\left[\mathrm{Cu}\left(\right.\right.$ trenpyz)] $\left(\mathrm{ClO}_{4}\right)_{2}$ (1)

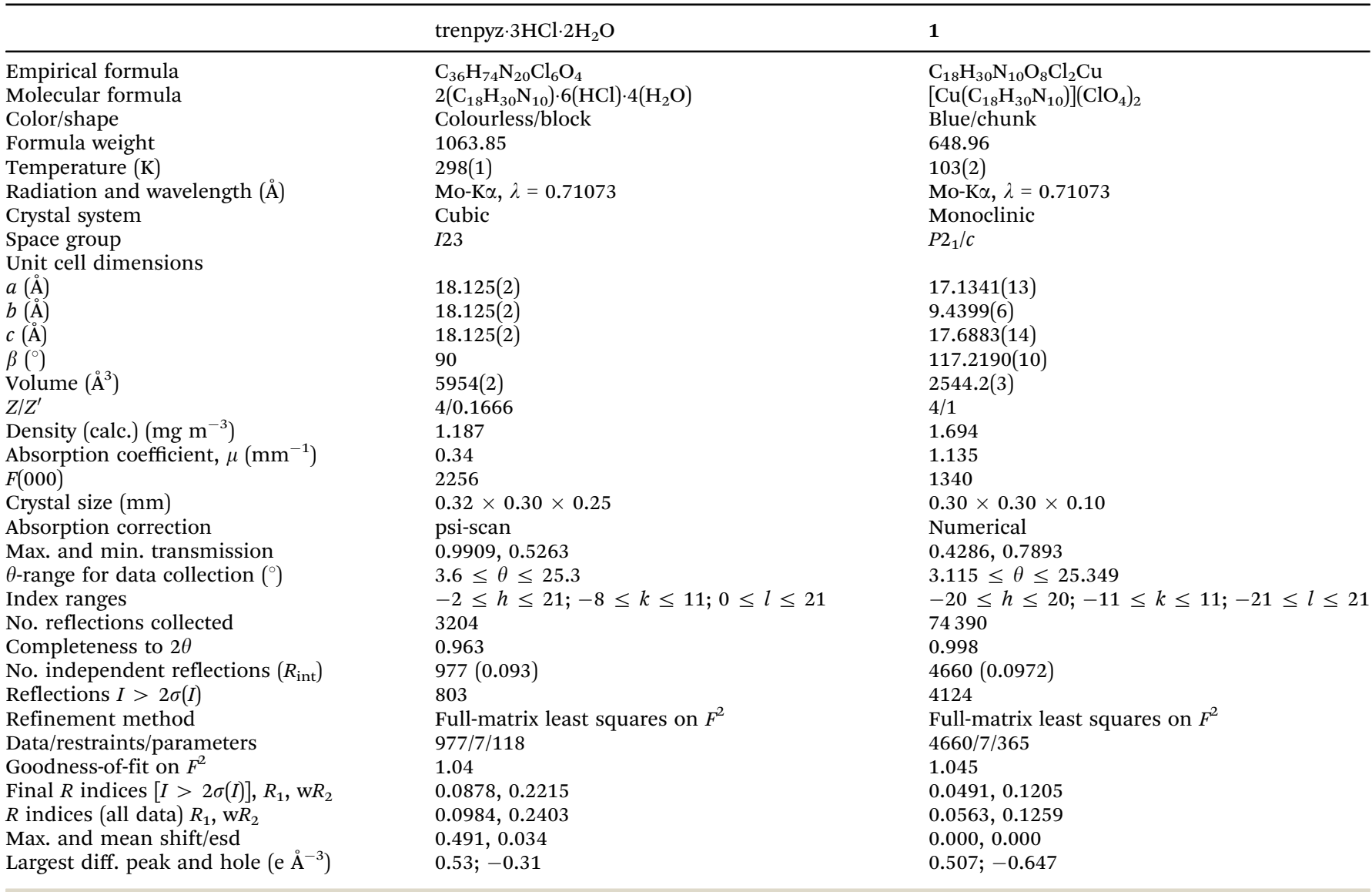

compound 1 were calculated using PLATON software. ${ }^{24}$ The graphical representation and the editing of CIF files were done by the Mercury ${ }^{25}$ and PublCif ${ }^{26}$ software, respectively.

\section{Potentiometric measurements}

The protonation and coordination equilibria were investigated by potentiometric titrations in aqueous solution $(I=0.1 \mathrm{M}$ $\mathrm{NaCl}$, and $T=298.0 \pm 0.1 \mathrm{~K})$ under Ar using an automatic titration set including a PC controlled Dosimat 665 (Metrohm) autoburette and an Orion 710A precision digital $\mathrm{pH}$-meter. The Metrohm Micro pH glass electrode $(125 \mathrm{~mm})$ was calibrated via the modified Nernst equation ${ }^{27}(1)$ :

$$
E=E_{0}+K \cdot \log \left[\mathrm{H}^{+}\right]+J_{\mathrm{H}} \cdot\left[\mathrm{H}^{+}\right]+\frac{J_{\mathrm{OH}} \cdot K_{\mathrm{w}}}{\left[\mathrm{H}^{+}\right]}
$$

where $J_{\mathrm{H}}$ and $J_{\mathrm{OH}}$ are fitting parameters in acidic and alkaline media for the correction of experimental errors, mainly due to the liquid junction and due to the alkaline and acidic errors of the glass electrode; $K_{\mathrm{w}}=10^{-13.75} \mathrm{M}^{2}$ is the auto-ionization constant of water. ${ }^{28}$ The parameters were calculated using the non-linear least squares method. In pure aqueous solutions titration was performed between $\mathrm{pH} 1.7$ and 11.0.

The complex formation is described by a general equilibrium process as follows:

$$
p \mathrm{M}+q \mathrm{H}+r \mathrm{~L} \stackrel{\beta_{\mathrm{M}_{p} \mathrm{H}_{q} \mathrm{~L}_{r}}}{\longleftrightarrow} \mathrm{M}_{p} \mathrm{H}_{q} \mathrm{~L}_{r}
$$

$$
\beta_{\mathrm{M}_{p} \mathrm{H}_{q} \mathrm{~L}_{r}}=\frac{\left[\mathrm{M}_{p} \mathrm{H}_{q} \mathrm{~L}_{r}\right]}{[\mathrm{M}]^{p}[\mathrm{H}]^{q}[\mathrm{~L}]^{r}}
$$

where $\mathbf{M}$ denotes the metal ion, $\mathbf{L}$ the non-protonated ligand molecule, and $\mathrm{H}$ stands for protons. Charges are omitted for simplicity, but can be easily calculated taking into account that the fully deprotonated ligand (at pH 10) is neutral. The corresponding formation constants $\left(\beta_{\mathrm{M}_{p} \mathrm{H}_{q} \mathrm{~L}_{r}} \equiv \beta_{p q r}\right)$ were calculated using the PSEQUAD computer program. ${ }^{29}$

The protonation constants were determined from four independent titrations (90 data points per titration), with a ligand concentration of $\sim 3 \times 10^{-3} \mathrm{M}$. The complex formation constants were evaluated from 5-7 independent titrations ( $\sim 90$ data points per titration). The metal-to-ligand ratios were $3: 2,1: 1$, and $1: 2$. The metal ion concentrations varied between 3 and $6 \times 10^{-3} \mathrm{M}$, depending on the metal-to-ligand ratio.

For $\mathrm{pH}$ determination in a $50 \%(\mathrm{~m} / \mathrm{m})$ ethanol-water mixture the $\mathrm{pH}$ glass electrode was calibrated by standard aqueous buffer solutions ( $\mathrm{pH}=4.0,7.0,9.0$, Sigma). The actual $\mathrm{pH}$ in this mixed solvent was determined by subtracting 0.21 units from the pH-reading, according to the method of Bates. ${ }^{30}$ The autoionization constant of water in this medium is $\mathrm{p} K_{\mathrm{w}}=14.84 .^{31}$ To determine the complex speciation in the $50 \%(\mathrm{~m} / \mathrm{m})$ ethanolwater mixture and at a $3 / 2$ metal-to-ligand ratio the characteristic UV-Vis spectra obtained above $\mathrm{pH} 2.2$ were used (above this $\mathrm{pH}$ the concentration of an uncomplexed ligand is negligible). 
Table 2 Formation constants and some derived equilibrium data of the proton and copper(I) complexes of trenpyz and some related ligands ( $T=298 \mathrm{~K}$, $I=0.1 \mathrm{M} \mathrm{(NaCl)}$, with estimated errors in parentheses (last digit))

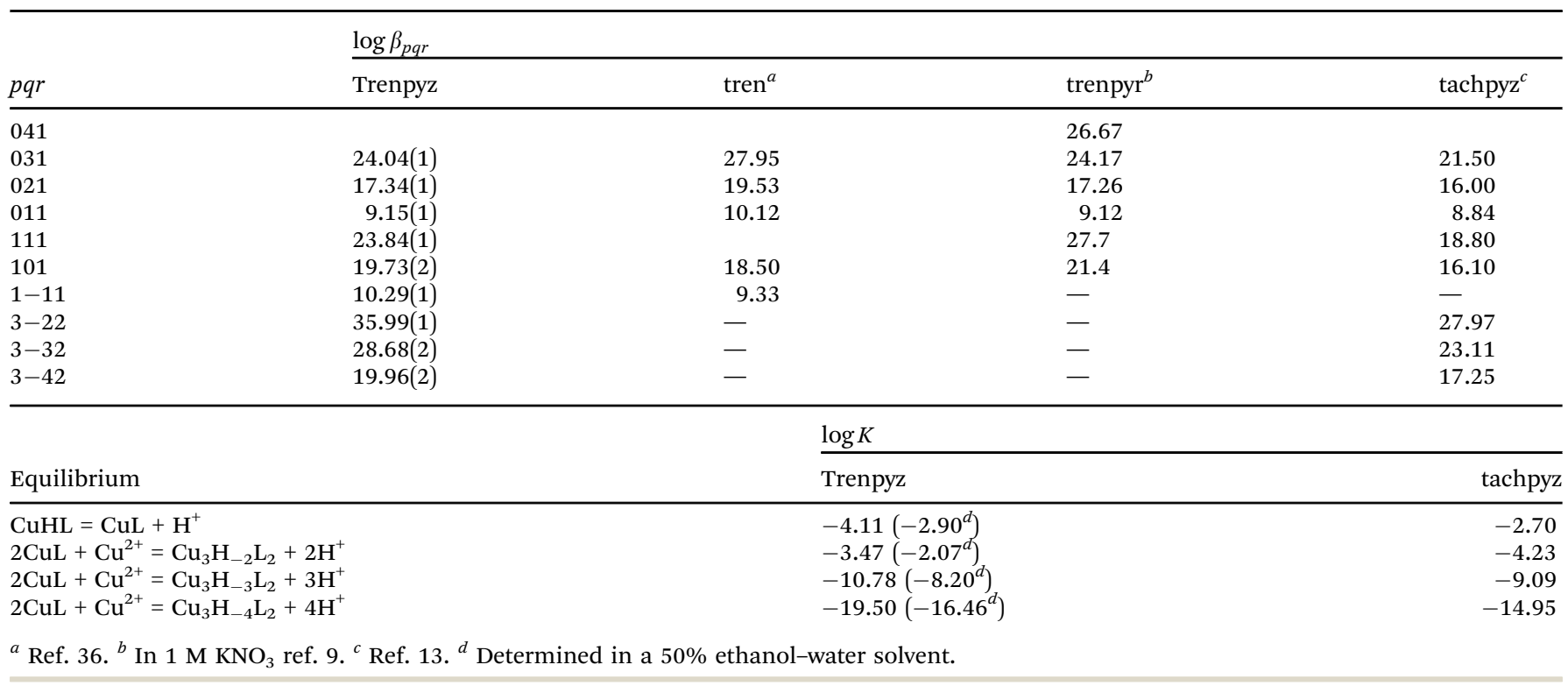

For the evaluation of the spectra using the PSEQUAD program $\mathrm{H}^{+}, \mathrm{CuL}$ and $\mathrm{Cu}^{2+}$ were set as basic components. In this way a correct speciation of complexes was obtained by refining the $\log K$ values for the equilibrium reactions listed in Table 2 .

\section{UV-Vis, CV, EPR and NMR measurements}

UV-Vis spectra were measured on a Thermo Scientific Evolution 200 spectrophotometer using a cell with a $1 \mathrm{~cm}$ optical path length. Similar concentrations were used as described above for the potentiometric titration. The individual UV-Vis spectra of the complexes were calculated using PSEQUAD. ${ }^{29}$

Cyclic voltammetric measurements were performed using a conventional three-electrode system in an Ar atmosphere and a PC-controlled Autolab-PGSTAT 204 potentiostat at $5 \mathrm{mV} \mathrm{s}^{-1}$ scan rate between -0.59 and $-1.41 \mathrm{~V}$. Platinum working, platinum auxiliary and $\mathrm{Ag} / \mathrm{AgCl} / \mathrm{KCl}(3 \mathrm{M})$ reference electrodes were used. Electrochemical potentials were converted into a normal hydrogen electrode scale by adding $0.21 \mathrm{~V}$ to the measured potential. ${ }^{32}$ The system was calibrated with aqueous solution of $5 \mathrm{mM} \mathrm{K} \mathrm{K}_{3} \mathrm{Fe}(\mathrm{CN})_{6}(0.1 \mathrm{M} \mathrm{NaCl})$. Cyclic voltammograms of the copper(II)-trenpyz $3 / 2$ system were measured at $298 \mathrm{~K}$ in a $50 \%(\mathrm{~m} / \mathrm{m})$ ethanol-water mixture at $\mathrm{pH}=7.2 \mathrm{using}$ $0.1 \mathrm{M}$ tetrabutylammonium nitrate as a background electrolyte.

The EPR spectra were recorded at room temperature and at $77 \mathrm{~K}$ using a BRUKER EleXsys E500 spectrometer (microwave frequency $9.81 \mathrm{GHz}$, microwave power $13 \mathrm{~mW}$, modulation amplitude $5 \mathrm{G}$, modulation frequency $100 \mathrm{kHz}$ ). The EPR spectra were determined in aqueous solutions, and were simulated using a spectral decomposition algorithm. ${ }^{33}$ Since a copper(II) salt used to make the stock solution was a natural mixture of isotopes, the spectrum of each species was calculated as the sum of spectra containing ${ }^{63} \mathrm{Cu}$ and ${ }^{65} \mathrm{Cu}$ weighted by their natural abundance. The copper and ligand coupling constants are given in units of gauss $\left(1 \mathrm{G}=10^{-4} \mathrm{~T}\right)$.
The ${ }^{1} \mathrm{H}$ NMR measurements were performed on a Bruker Avance DRX 500 spectrometer. The spectra were recorded at $25{ }^{\circ} \mathrm{C}$ in a $10 \% \mathrm{D}_{2} \mathrm{O} / \mathrm{H}_{2} \mathrm{O}$ or $100 \% \mathrm{D}_{2} \mathrm{O}$ solution, at ligand concentrations of $\sim 3.0 \times 10^{-3} \mathrm{M}$ with a tube diameter of $5 \mathrm{~mm}$. The chemical shifts $(\delta)$ were measured relative to $\mathrm{SiMe}_{4}$. Data were processed using the Topspin 2.0 software package (Bruker).

\section{Catechol oxidase activity measurements}

The oxidation of 3,5-ditertbuthylcatechol $\left(\mathrm{H}_{2} \mathrm{dtbc}\right)$ in the presence and absence of the copper-trenpyz system was followed spectrophotometrically on a Thermo Scientific Evolution 200 spectrophotometer at the absorption maximum of the product 3,5-di-tert-butyl-o-benzoquinone (dtbq, $400 \mathrm{~nm}, \varepsilon=1900 \mathrm{M}^{-1} \mathrm{~cm}^{-1}$ ). Due to the low solubility of dtbq, a $50 \mathrm{~m} / \mathrm{m} \%$ ethanol-water mixture was used as the solvent. The $\mathrm{pH}$ of the solution was set by buffers (0.02 M CHES-HEPES, $I=0.1 \mathrm{M}, T=298 \mathrm{~K}$ ), and dioxygen-saturated ethanol was used to prepare the reaction mixture. To determine the dependence of the rate on the dioxygen concentration, a mixture of dioxygen- and argon saturated solutions was used. After mixing the two phases, the solution was equilibrated at $298 \mathrm{~K}$ for $2-3$ minutes, and the reaction was initiated by adding the substrate. The auto-oxidation of 3,5-di-tert-butylcatechol was also determined for each substrate concentration and the $\mathrm{pH}$ value to be subtracted from the overall effect in order to obtain the pseudo-first order reaction constant $k_{\text {obs,corr }}$ Kinetic studies were carried out using the method of initial rates, up to $4 \%$ conversion. The reported data are averages of three parallel experiments. The maximum deviation from the main value did not exceed $10 \%$.

The binding of 4-nitrocatechol $\left(\mathrm{H}_{2} 4 \mathrm{nc}\right)$ to the trinuclear complexes was studied under the same conditions as used for kinetic measurements. The formation of hydrogen peroxide during the oxidation of $\mathrm{H}_{2} \mathrm{dtbc}$ was demonstrated and quantified in aqueous solution using $\mathrm{TiOSO}_{4}$ via the formation of the 
$\left[\mathrm{Ti}\left(\mathrm{O}_{2}\right)(\mathrm{OH})\right]^{+}$complex $\left(\varepsilon(408 \mathrm{~nm})=935 \mathrm{M}^{-1} \mathrm{~cm}^{-1}\right)$. In a typical experiment $25 \mathrm{ml}$ of the reaction mixture was prepared $(T=298 \mathrm{~K}$, 0.02 M CHES-HEPES, $\left.I=0.1 \mathrm{M}, \mathrm{pH}=8.1,\left[\mathrm{Cu}^{2+}\right] /[\mathbf{L}]=3: 2\right)$ and the reaction was initiated by the addition of $\mathrm{H}_{2} \mathrm{dtbc}\left(\left[\mathrm{H}_{2} \mathrm{dtbc}\right]_{0}=\right.$ $0.1 \mathrm{mM}) . \mathrm{O}_{2}$ gas was bubbled through the solution. After different time intervals $(8,16,35,60,90 \mathrm{~min}) 4.5 \mathrm{ml}$ of the sample was taken and treated with $0.5 \mathrm{ml}$ of $20 \% \mathrm{H}_{2} \mathrm{SO}_{4}$ to freeze the reaction. Afterwards it was extracted with $2 \times 5 \mathrm{ml}$ of dichloromethane to remove the remaining substrate and the quinone product. The aqueous phase was treated with excess $\mathrm{TiOSO}_{4}$, and the UV-Vis spectrum of the resulting solution was recorded. Parallel with this determination, the formation of dtbq was also quantified under the same conditions, without the extraction step. After adding $20 \% \mathrm{H}_{2} \mathrm{SO}_{4}$ and ethanol to freeze the reaction and to obtain a $50 \mathrm{~m} / \mathrm{m} \%$ ethanol-water mixture, the UV-Vis spectrum of the sample was recorded.

\section{Results and discussion}

\section{Crystal structure of trenpyz}

The triply protonated ligand trenpyz $\cdot 3 \mathrm{HCl} \cdot 2 \mathrm{H}_{2} \mathrm{O}$ crystallized in the cubic 121 space group. Bond distances and angles (Table S1 in the ESI $\dagger$ ) are normal and unstrained. Actually, in this cubic lattice the asymmetric unit contains one arm of the ligand and two different chloride and two water places. The N1-C2-C3-N4 torsion angle is $70.7(9)^{\circ}$ (Fig. 1 and Table S1, ESI $\dagger$ ), which results in the formation of a tripodal cage suitable to encapsulate a chloride ion by three $\mathrm{H}$-bonds to the secondary nitrogen atoms. The $(\mathrm{N}-\mathrm{H})^{+} \ldots \mathrm{Cl} 1$ and $\mathrm{N}-\mathrm{Cl} 1$ distances are $2.337 \AA$ and $3.216 \AA$, respectively, with $\mathrm{N}-\mathrm{H} \cdots \mathrm{Cl} 1$ angles of $169.56^{\circ}$. The other two, non-encapsulated chlorides also serve as acceptors for the secondary nitrogen atoms $\left((\mathrm{N}-\mathrm{H})^{+} \cdots \mathrm{Cl} 2\right.$ and $\mathrm{N}-\mathrm{Cl} 2$ distances are $2.214 \AA$ and $3.091 \AA$, respectively), and are involved in further $\mathrm{H}$-bonds with pyrazol $\mathrm{NH}$ and water protons (Fig. S1, ESI $\dagger$ ). The chloride ion bound to the tripodal, $\mathrm{C}_{3}$-symmetric cavity induces

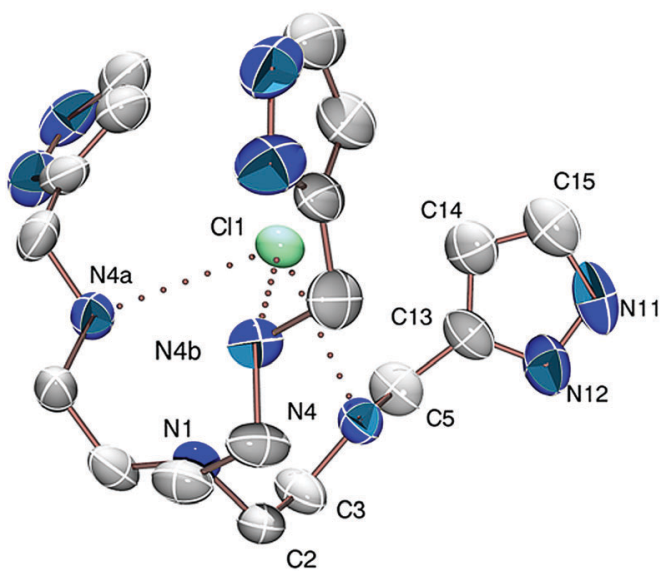

Fig. 1 Molecular structure of trenpyz with atom numbering. A chloride ion bound in the tripodal cavity is also shown. Other counter ions, water molecules and hydrogen atoms are omitted for clarity. Displacement parameters are drawn at $50 \%$ probability level. The distance of Cl1-N4 is $3.216 \AA$ A. Symmetry operators: (a) $y, z, x$; (b) $z, x, y$. pre-organization of the ligand, similar to that needed for metal ion binding.

\section{Crystal structure of $[\mathrm{Cu}($ trenpyz $)]\left(\mathrm{ClO}_{4}\right)_{2}$}

The complex crystallized in the monoclinic $P 2_{1} / c$ space group with the inclusion of two perchlorate anions (the packing arrangement is shown in Fig. S2, ESI $\dagger$ ). The Ortep representation of the $[\mathrm{Cu}(\text { trenpyz })]^{2+}$ cation is shown in Fig. 2. Some selected structural parameters of the metal complex cation are collected in the legend of Fig. 2. In the pentacoordinated structure four nitrogen atoms are coordinating to the copper centre in short distances (1.97-2.07 $\AA$ ), while the Cu1-N8 bond is slightly longer (2.15 $\AA$ ). The geometry around the metal ion is strongly distorted trigonal bipyramidal $(\tau=0.56) .{ }^{34}$

The two non-coordinated pyrazole rings are involved in intramolecular hydrogen bonds with $\mathrm{N}-\mathrm{H}$ protons of the neighbouring side chains which stabilize their position in the crystal structure. The position of the three 'pod' is very different; the angles between the pyrazole ring planes are 53.5(2), 57.1(2) and 76.7(2). The N2, N5, N8 nitrogen atoms are pseudo chiral centres, and the crystal structure contains the SSS and RRR configurations in a racemic mixture.

This is the first published crystal structure for metal complexes of trenpyz; therefore it can be compared only to those of some related pyridine or imidazole substituted tren derivatives. The complex $[\mathrm{Cu} \text { (Htrenpyr) }]^{3+}$, in which one of the secondary nitrogen atoms is protonated, has square pyramidal geometry. ${ }^{9}$ The non-protonated (neutral) trenpyr, similarly to its imidazole derivative tris\{2-[2-(1-methyl)imidazolyl]-methylaminoethyl\}amine (trenmimi), forms a trinuclear complex with a $3 / 2$ metal-to-ligand ratio. ${ }^{9,10}$ The central copper(II), coordinated by one arm of each

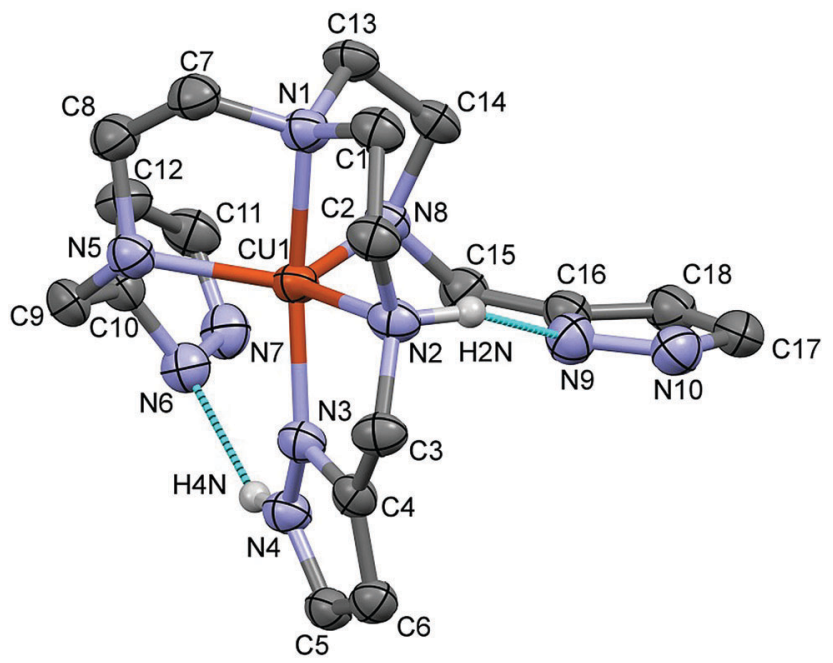

Fig. 2 Molecular structure of the $\left[\mathrm{Cu}(\text { trenpyz) }]^{2+}\right.$ cation of 1 with atom numbering. Intramolecular hydrogen bonds are shown with blue lines, other hydrogens are omitted for clarity. Displacement parameters are drawn at $50 \%$ probability level. Selected bond lengths $(\AA)$ and angles $\left({ }^{\circ}\right)$ : Cu1-N1 2.027(3), Cu1-N2 2.042(3), Cu1-N3 1.975(3), Cu1-N5 2.076(3), Cu1-N8 2.148(3), N1-Cu1-N2 84.8(1), N1-Cu1-N8 84.5(1), N1-Cu1-N5 85.6(1), N2-Cu1-N5 132.1(1), N5-Cu1-N8 114.8(1), N2-Cu1-N8 110.7(1), N3-Cu1-N1 165.6(1). 
ligand molecules, is octahedral; the peripheral copper(II) centres have distorted square pyramidal geometry. The Schiff-base derivative of trenmimi forms octahedral copper(II) species. ${ }^{35}$ Among the above complexes, the $4 \mathrm{~N}$ donor set of the tren subunit is coordinated to the same metal ion only in $\left[\mathrm{Cu}(\text { trenpyz) }]^{2+}\right.$, which enforces its trigonal bipyramidal geometry.

The closest structural analogue of crystal 1 is the copper(II) complex of the potentially heptadentate (N4O3) tris(2-hydroxybenzylaminoethyl)amine. ${ }^{12}$ In this structure (ref. code OREGAU), beside the amino nitrogens a side chain phenolic oxygen is also coordinated. The comparison of the two structures is shown in Fig. S3 (ESI $\dagger$ ). The chirality of the three amino groups in OREGAU is the same as in 1, and similarly, intramolecular hydrogen bonds stabilize the positions of the two non-coordinated side chains. For OREGAU, the geometry is closer to the trigonal bipyramid ( $\tau=0.67$ ), due to the six-membered chelate ring formed with the participation of phenolic oxygen (in $\mathbf{1}$ the pyrazole nitrogen is involved in a five-membered ring, Fig. 2).

The main secondary interactions in the crystal structure of 1 are hydrogen bonds between $\mathrm{N}-\mathrm{H}$ or $\mathrm{C}-\mathrm{H}$ hydrogens and the perchlorate oxygens. Despite that, one perchlorate anion was found to be able to rotate around the $\mathrm{Cl}-\mathrm{O}$ axis resulting in a disordered structure. The hydrogen bond connections in $\mathbf{1}$ are depicted in Fig. S4 (ESI $\dagger$ ), some selected data are collected in Table S2 (ESI $\dagger)$.

\section{Solution chemical studies}

The protonation constants of trenpyz are listed in Table 2 . Despite a number of protonable nitrogen atoms in trenpyz, only three (de)protonation processes were detected between $\mathrm{pH} 2$ and 11, which belong to the secondary amines. Therefore, the protonation constants of trenpyz are directly comparable with those of tren and trenpyr (Table 2), indicating a notable electronwithdrawing effect of the pyrazole rings, similar to those of the pyridine rings.

The complex formation in the copper(II)-trenpyz system was studied at $\mathbf{M} / \mathbf{L}$ ratios of $1 / 2,1 / 1,3 / 2$ and 2/1. At a twofold metal ion excess precipitate formation was detected above $\mathrm{pH} 6$, but at lower $\mathbf{M} / \mathbf{L}$ ratios the solution was clear within the $\mathrm{pH}$-range studied. Since in equimolar $\mathrm{Cu}$ (II)-L solution, the concentration of uncomplexed copper(II) at the beginning of pH-metric titration $(\mathrm{pH} \sim 1.8)$ was relatively low $(x \sim 0.3$, Fig. 3A), $\mathrm{pH}$-dependent Vis-near IR spectra were also recorded between pH 0.7 and 11.2 (Fig. 4A) in order to determine the correct formation constants. The combined evaluation of $\mathrm{pH}$-potentiometric and spectrophotometric data indicated the formation of three mononuclear ( $\left.\mathrm{CuHL}, \mathrm{CuL}, \mathrm{CuH}_{-1} \mathbf{L}\right)$ and three trinuclear $\left(\mathrm{Cu}_{3} \mathrm{H}_{-2} \mathbf{L}_{2}\right.$, $\mathrm{Cu}_{3} \mathrm{H}_{-3} \mathbf{L}_{2}$ and $\mathrm{Cu}_{3} \mathrm{H}_{-4} \mathbf{L}_{2}$ ) complexes in the copper(II)-trenpyz system. The distribution curves of these complexes are depicted in Fig. 3; their formation constants are listed in Table 2.

In equimolar solution the highly stable CuHL is the dominant species around $\mathrm{pH}$ 3. Its stability is considerably higher than that of the corresponding complex of tachpyz (Table 2), even considering the differences in the basicity of the ligands. This indicates the coordination of an additional donor group, i.e. the tertiary nitrogen atom in CuHL. The two absorption bands observed in the Vis-near IR spectrum of CuHL (Fig. 4A and Fig. S5, ESI $\dagger$ ) indicate square pyramidal geometry around the metal ion with relatively strong apical coordination. ${ }^{8,13}$ This conclusion is also supported by the EPR parameters of the species CuHL (Fig. 5 and Table 3). The deprotonation of CuHL $(\mathrm{p} K=4.13)$ results in the formation of $\mathrm{CuL}$, a unique species between $\mathrm{pH} 6$ and 8. During this deprotonation both the Vis-near IR (Fig. 4 and Fig. S5, ESI $\dagger$ ) and the low temperature EPR spectra (Fig. 5) indicate fundamental changes in the coordination sphere of copper(II). Both the typical $\mathrm{d}-\mathrm{d}$ transitions and the 'reversed' order of $g$-values (Table 3 ) indicate distorted trigonal bipyramidal geometry around the metal ion, similar to the crystal structure of complex 1.

Considering that trenpyz offers seven nitrogen atoms for the formation of fused chelate rings, its $5 \mathrm{~N}$ coordination in trigonal bipyramidal geometry is surprising; especially, since this geometry has not been observed in solution for copper(II) complexes of other potentially N7 coordinating tren derivatives. ${ }^{9,10,35}$ It seems that in the present case the strong coordinating ability of the tren subunit is the governing factor, and the pyrazole rings occupy only the coordination position left free by the amino nitrogens.

In order to compare the metal ion binding abilities of tren, trenpyz and tachpyz, we calculated the conditional stability constants at $\mathrm{pH} 7.4\left(K_{\text {cond }}(\mathrm{pH})=\left(\sum\left[\mathrm{MH}_{x} \mathrm{~L}\right]\right) /\left(\left[\mathrm{M}^{2+}\right]_{\text {free }}\right) \times\right.$ $\left.\left(\sum\left[\mathrm{H}_{x} \mathrm{~L}\right]_{\text {free }}\right)\right)$. The corresponding $\log K_{\text {cond }}(\mathrm{pH}=7.4)$ values are $12.6,{ }^{36} 17.1$ and $14.9,{ }^{13}$ respectively. The more than 4 orders of
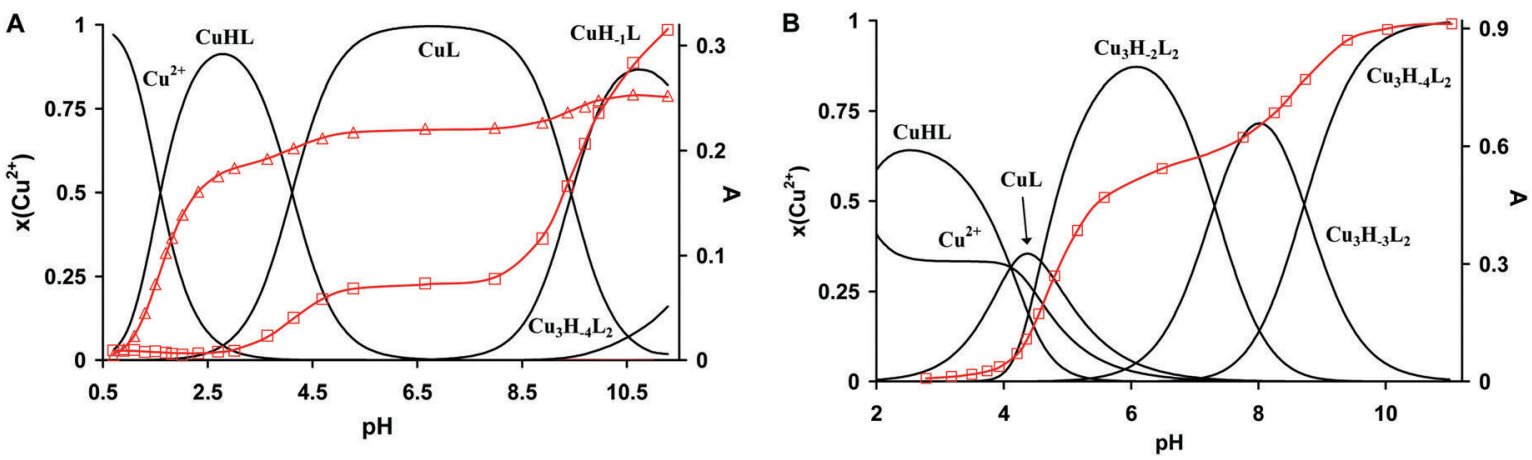

Fig. 3 Speciation diagram of the copper(II)-L 1:1 (A) and 3:2 (B) systems, and the $\mathrm{pH}$-dependent changes of absorbances at $420 \mathrm{~nm}$ (square) and $628 \mathrm{~nm}$ (triangle). $T=298 \mathrm{~K}, I=0.1 \mathrm{M} \mathrm{NaCl},\left[\mathrm{Cu}^{2+}\right]_{\text {tot }}=1.495 \mathrm{mM}$ (A), $2.193 \mathrm{mM}$ (B). 



Fig. 4 Effect of $\mathrm{pH}$ on the UV-Vis/NIR spectra of the copper(II)-trenpyz $1: 1$ (A) and $3 / 2$ (B) systems $(T=298 \mathrm{~K}, I=0.1 \mathrm{M}(\mathrm{NaCl})$, [trenpyz] $=$ $1.554 \mathrm{mM})$. (A) $\left[\mathrm{Cu}^{2+}\right]_{\text {tot }}=1.495 \mathrm{mM}, \mathrm{pH}=0.7-11.3$, the blue, red and green spectra correspond to $\mathrm{CuHL}, \mathrm{CuL}$ and $\mathrm{CuH}_{-1} \mathrm{~L}$, respectively; (B) $\left[\mathrm{Cu}^{2+}\right]=$ $2.193 \mathrm{mM}$, [trenpyz] $=1.554 \mathrm{mM}, \mathrm{pH}=2.3-11.0$, the blue and red spectra correspond to $\mathrm{Cu}_{3} \mathrm{H}_{-2} \mathrm{~L}_{2}$ and $\mathrm{Cu}_{3} \mathrm{H}_{-4} \mathrm{~L}_{2}$.

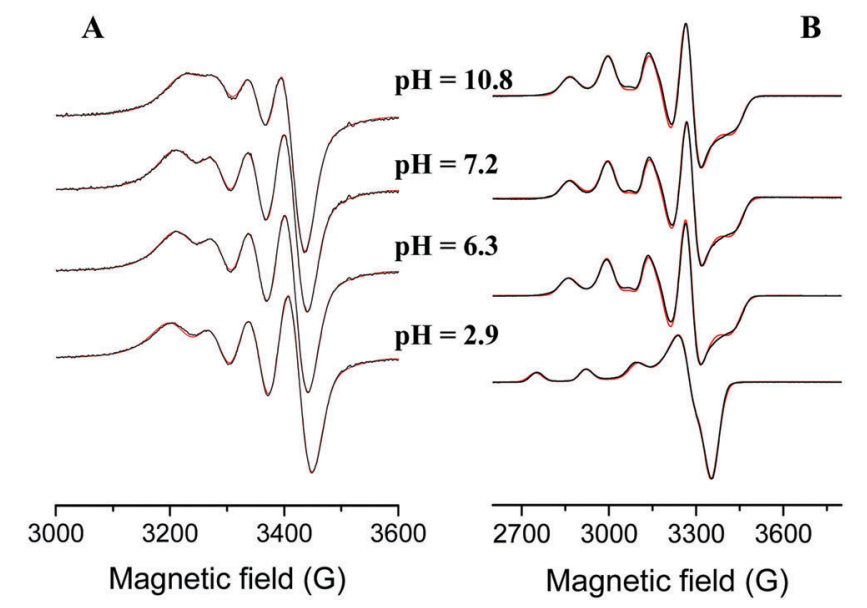

Fig. 5 Experimental (red) and simulated (black) EPR spectra of the copper(II) $-\mathbf{L} 1 / 1$ system at room temperature (A) and at $77 \mathrm{~K}(\mathrm{~B})$. ([L] $=$ $\left.\left[\mathrm{Cu}^{2+}\right]=2.96 \mathrm{mM}, \mathrm{I}=0.1 \mathrm{M}(\mathrm{NaCl})\right)$.

magnitude higher conditional stability constant of $\mathrm{CuL}$ compared to $\mathrm{Cu}$ (tren) confirms the additional coordination of a pyrazole ring. On the other hand, tachpyz, derived from the tridentate tripodal platform tach, is a considerably weaker copper(II) binder, despite the $5 / 6 \mathrm{~N}$ coordination in $\mathrm{Cu}\left(\right.$ tachpyz) ${ }^{13}$
Above $\mathrm{pH} 8$ the potentiometric data indicated further deprotonation and the formation of $\mathrm{CuH}_{-1} \mathbf{L}$. Although both the Vis-near IR and EPR spectra (Fig. 4, 5 and Table 3) indicate some differences between $\mathrm{CuL}$ and $\mathrm{CuH}_{-1} \mathbf{L}$, the typical features of trigonal bipyramidal geometry are retained. The $\mathrm{p} K$ of this deprotonation (9.56) is only slightly higher than that of $\mathrm{Cu}($ tren) ( $\mathrm{p} K=9.17$, Table 2), in which the proton loss of a water molecule bound in the fifth coordination position takes place. ${ }^{36}$ Considering that in $\mathrm{CuH}_{-1} \mathbf{L}$ the fifth coordination position is occupied, and that a similar process is absent for the $\mathrm{Cu}$ (trenpyr) complex up to $\mathrm{pH} 11,{ }^{9}$ the observed deprotonation is most probably related to the copper-bound pyrazole ring, i.e. the formation of a pyrazolate anion. Indeed, deprotonation results in the development of a CT band around $420 \mathrm{~nm}$ with medium intensity (Fig. 3, 4 and Fig. S5, ESI $\dagger$ ), which is very similar to the pyrazolate $\rightarrow \mathrm{Cu}(\mathrm{II})$ transition reported earlier for some mononuclear copper(II) complex. ${ }^{37}$

The presence of a mono-coordinated pyrazolate ring creates the possibility for the formation of oligonuclear complexes, through pyrazolate bridges, which was indeed observed above pH 10 even in equimolar solutions. Obviously, at a $3 / 2 \mathrm{Cu}(\mathrm{II}) / \mathbf{L}$ ratio their formation is more pronounced and three trinuclear complexes can be identified (Fig. 3B).

The formation of mono- and trinuclear nuclear complexes was confirmed by ESI and MALDI-TOF MS (Fig. 6). In equimolar solution the ESI MS spectrum (Fig. 6A) clearly shows the presence of $\left[\mathrm{CuH}_{-1} \mathbf{L}\right]^{+}\left(=\left[\mathrm{CuN}_{10} \mathrm{C}_{18} \mathrm{H}_{29}\right]^{+}\right)$. Although the isotopic distribution pattern obtained for the same species by MALDI-TOF MS is very similar (Fig. 6B), the monoisotopic mass is a unit higher. This observation reflects the reduction of $\mathrm{Cu}^{2+}$ to $\mathrm{Cu}^{+}$and the corresponding uptake of one proton during the ionization processes. Identical observations were reported in the literature related to MALDI-TOF MS studies of many copper(II) complexes, formed with cyclen/cyclam derivatives, ${ }^{38}$ some pseudo-peptides ${ }^{39}$ and peptides. ${ }^{40,41}$ Accordingly, reduced copper centers were observed for the trinuclear species too. Its MALDI-TOF MS spectrum (Fig. 6C) indicates the presence of the molecular ion $\left\{\left[\mathrm{Cu}_{3} \mathrm{~N}_{20} \mathrm{C}_{36} \mathrm{H}_{57}\right] \mathrm{Na}\right\}^{+}$.

Around pH 6 the doubly deprotonated $\mathrm{Cu}_{3} \mathrm{H}_{-2} \mathbf{L}_{2}$ complex is dominant, and its stepwise deprotonation $(\mathrm{p} K=7.56,8.62)$ results in the formation of $\mathrm{Cu}_{3} \mathrm{H}_{-4} \mathbf{L}_{2}$, a unique species above pH 10 (Fig. 3B). Above pH 4, parallel with the formation of trinuclear complexes, the color of the solution shows gradual changes from blue to green than to brownish green, due to the development of an intense charge transfer (CT) band around $420 \mathrm{~nm}$ (Fig. 4B and Fig. S6, ESI $\dagger$ ). Considering the structure of trenpyz, the formation of such intense CT bands is consistent only with the formation of pyrazolate-bridges within the trinuclear complexes $\mathrm{Cu}_{3} \mathrm{H}_{-x} \mathbf{L}_{2}(x=2,3,4)$. Similar observations were made in the $\mathrm{Cu}(\mathrm{II})$-tachpyz system too; therefore the structure of $\mathrm{Cu}_{3} \mathrm{H}_{-4} \mathbf{L}_{2}$ should be analogous to the crystallographically characterized $\left[\mathrm{Cu}_{3} \mathrm{H}_{-4}(\text { tachpyz })_{2}\right]\left(\mathrm{ClO}_{4}\right)_{2} \cdot 5 \mathrm{H}_{2} \mathrm{O} .{ }^{13}$

The trinuclear complexes have high thermodynamic stability, e.g. $\log K\left(2 \mathrm{CuH}_{-1} \mathbf{L}+\mathrm{Cu}^{2+}=\mathrm{Cu}_{3} \mathrm{H}_{-2} \mathbf{L}_{2}\right)=15.78$. Since the formation of $\mathrm{Cu}_{3} \mathrm{H}_{-2} \mathbf{L}_{2}$ is induced by the deprotonation of $\mathrm{CuL}=\mathrm{CuH}_{-1} \mathbf{L}+\mathrm{H}^{+}$, the latter equilibrium can be regarded as an allosteric process, i.e. the formation of the trinuclear 
Table 3 Spectroscopic parameters of the different copper(II) complexes observed, with estimated errors in parentheses (last digit)

\begin{tabular}{llllll}
\hline Complex & $\lambda_{\text {max }}^{\mathrm{d}-\mathrm{d}}(\mathrm{nm})$ & $g_{\mathrm{o}}$ & $A_{\mathrm{o}}(\mathrm{G})$ & $g_{x}, g_{y}, g_{z}$ & $A_{x}, A_{y}, A_{z}(\mathrm{G})$ \\
\hline $\mathrm{CuHL}$ & 626 & $2.105(1)$ & $64.7(5)$ & $2.053(2), 2.053(2), 2.236(2)$ & $19(1), 19(1), 170(1)$ \\
$\mathrm{CuL}$ & 880 & $2.114(1)$ & $59.4(1)$ & $2.195(2), 2.134(2), 2.010(1)$ & $134(2), 85(2), 50(1)$ \\
$\mathrm{CuH}_{-1} \mathbf{L}$ & 790 & & & & \\
$\mathrm{Cu}_{3} \mathrm{H}_{-2} \mathbf{L}_{2}$ & 640 & $2.111(1)$ & $52.8(5)$ & $2.194(2), 2.132(2), 2.010(1)$ & $134(2), 82(2), 54(1)$ \\
$\mathrm{Cu} 3 H_{-3} \mathbf{L}_{2}$ & 756 & $2.114(1)$ & $60.8(5)$ & $2.196(2), 2.134(2), 2.013(2), 2.104^{a}$ & $135(2), 83(2), 44(2)$ \\
$\mathrm{Cu}_{3} \mathrm{H}_{-4} \mathbf{L}_{2}$ & 750 & & & & \\
& $\sim 750$ & $2.115(1)$ & $60.4(5)$ & $2.196(2), 2.133(2), 2.010(2), 2.097^{a}$ & $134(2), 83(2), 45(2)$ \\
& $\sim 750$ (shoulder) & $2.115(1)$ & $56.3(5)$ & $2.196(2), 2.133(2), 2.010(2), 2.100^{a}$ & $134(2), 83(2), 45(2)$
\end{tabular}

${ }^{a}$ Trinuclear complex spectra were described as the sum of mononuclear and broad singlet type spectra for which only $g_{\mathrm{o}}$ values could be determined.

complex(es) is under the allosteric control of the two copper(II) ions bound in $\mathrm{CuL} / \mathrm{CuH}_{-1} \mathbf{L}$.

Surprisingly, the species $\mathrm{Cu}_{3} \mathrm{H}_{-2} \mathbf{L}_{2}$ formed around pH 6 has well resolved EPR spectra both at $298 \mathrm{~K}$ and $77 \mathrm{~K}$; however the EPR signal intensity gradually decreases with increasing $\mathrm{pH}$, which is more pronounced at room temperature (Fig. 7A and B). On the other hand, the EPR intensity passes through a maximum with increasing $\mathrm{Cu}(\mathrm{II}) / \mathbf{L}$ ratios (at a constant concentration of $\mathbf{L}$ ), and the maximum is observed at a $1 / 1$ $\mathrm{Cu}(\mathrm{II}) / \mathbf{L}$ ratio (Fig. $7 \mathrm{C}$ and $\mathrm{D}$ ). At $\mathrm{pH} 6.4$ the intensities observed at 0.5 and $1.5 \mathrm{Cu}(\mathrm{II}) / \mathbf{L}$ ratios are nearly identical (Fig. 7C), i.e. at a $3 / 2 \mathrm{Cu}(\mathrm{II}) / \mathbf{L}$ ratio only $1 / 3$ of the expected intensity can be observed. The EPR spectra of trinuclear complexes at $77 \mathrm{~K}$ can be well described as superposition of a broad singlet and the signal of mononuclear complexes (Table 3 and Fig. 7B). At room temperature the singlet is even more broadened and only the mononuclear spectra appear.

The EPR parameters obtained from the simulation are collected in Table 3.

All these facts are in agreement with an antiferromagnetically coupled tricopper(II) core with the total spin of $S=\frac{1}{2}$. Since the pyrazolato-bridged tricopper core in this case should have linear arrangement, the above facts imply that the central copper(II) is strongly coupled with one of the two peripheral copper(II) ions. The detectable EPR spectrum is not uncommon for tricopper(II) complexes, ${ }^{42}$ although the sharp and relatively well-resolved spectra are rare, and indicate that the two peripheral copper(II) ions are magnetically equivalent. At pH 10 (Fig. 7D), the increasing $\mathrm{Cu}(\mathrm{II}) / \mathrm{L}$ ratios result in considerably broadened EPR lines (loss of intensity). In principle, such broadening might be due to intramolecular exchange phenomena, which is faster in the complexes with $3 / 4$ pyrazolato bridges between the copper(II) centres. It is worth pointing out that the low temperature EPR spectra of the trinuclear complexes (Fig. 7B) clearly indicate that the peripheral copper(II) centres of the trinuclear complexes have trigonal bipyramidal geometry.

Although in the $\mathrm{Cu}(\mathrm{II})-\mathbf{L}$ and $\mathrm{Cu}(\mathrm{II})-\operatorname{tachpyz}^{13} 3 / 2$ systems similar trinuclear complexes are formed, the variation of the trigonal platforms results in fundamental differences in their relative stabilities. In this respect, the equilibrium constants $\left(\log K\right.$, see Table 2) of the reactions $2 \mathrm{CuL}+\mathrm{Cu}^{2+}=\mathrm{Cu}_{3} \mathrm{H}_{-x} \mathrm{~L}_{2}+x \mathrm{H}^{+}$ $(x=2,3,4)$ for trenpyz and tachpyz are worth comparing: $\Delta \log K=\log K_{\text {trenpyz }}-\log K_{\text {tachpyz }}=+0.76(x=2),-1.69(x=3)$ and $-4.55(x=4)$. Consequently, although the appearance of $\mathrm{Cu}_{3} \mathrm{H}_{-2} \mathrm{~L}_{2}$ is more preferred for trenpyz than for tachpyz, the formation of the subsequent complexes is considerably less favoured. The reason for this deviation is the different denticities of the two ligands. Due to the higher number of available donor atoms in trenpyz four 'free' pyrazole rings are available in $\mathrm{Cu}_{3} \mathrm{H}_{-2} \mathbf{L}_{2}$, which in turn are able to significantly stabilize the two-fold deprotonated trinuclear complex by coordination to the central metal ion (Scheme 2), in contrast to the $\mathrm{Cu}_{3} \mathrm{H}_{-2}(\text { tachpyz })_{2}$ species. In addition, during the formation of the trenpyz complexes containing $3 / 4$ pyrazolato bridges, one/two secondary amines should be displaced from the coordination spheres of the peripheral copper(II) centers (Scheme 2). Since similar donor atom displacement does not occur in the case of tachpyz, the formation of its trinuclear complexes is more favored. As a consequence, the speciation of trinuclear complexes is significantly different in the two systems. $\mathrm{Cu}_{3} \mathrm{H}_{-2} \mathbf{L}_{2}$ is a dominant species between pH 5 and 7, while the formation of three- and four-fold deprotonated complexes of trenpyz is shifted by more than two $\mathrm{pH}$ units to the higher $\mathrm{pH}$, as compared to the corresponding tachpyz species (Fig. 8).

\section{Kinetic studies}

Our intention was to compare both the coordination chemical properties and the catechol oxidase activity of $\mathrm{Cu}(\mathrm{II})$-tachpyz and $\mathrm{Cu}(\mathrm{II})$-trenpyz complexes, in order to explore the role of tripodal platforms in the stability, structure and enzyme mimicry of these species. To this end we studied the ability of $\mathrm{Cu}(\mathrm{II})$-trenpyz complexes to promote the oxidation of di-tert-butyl-catechol, a widely used substrate to study catechol oxidase activity, and compared to that we obtained earlier for the $\mathrm{Cu}(\mathrm{II})$-tachpyz system. ${ }^{13}$

In order to understand the activation of dioxygen by metalloenzymes a large number of biomimetic models of catechol oxidase have been studied. ${ }^{14,43}$ Catechol oxidases are type 3 copper enzymes; ${ }^{44,45}$ therefore mainly dinuclear complexes were used, ${ }^{46-51}$ but several mono- ${ }^{52,53}$ and trinuclear ${ }^{13,41,54}$ species were also reported to have important catechol oxidase activity. 

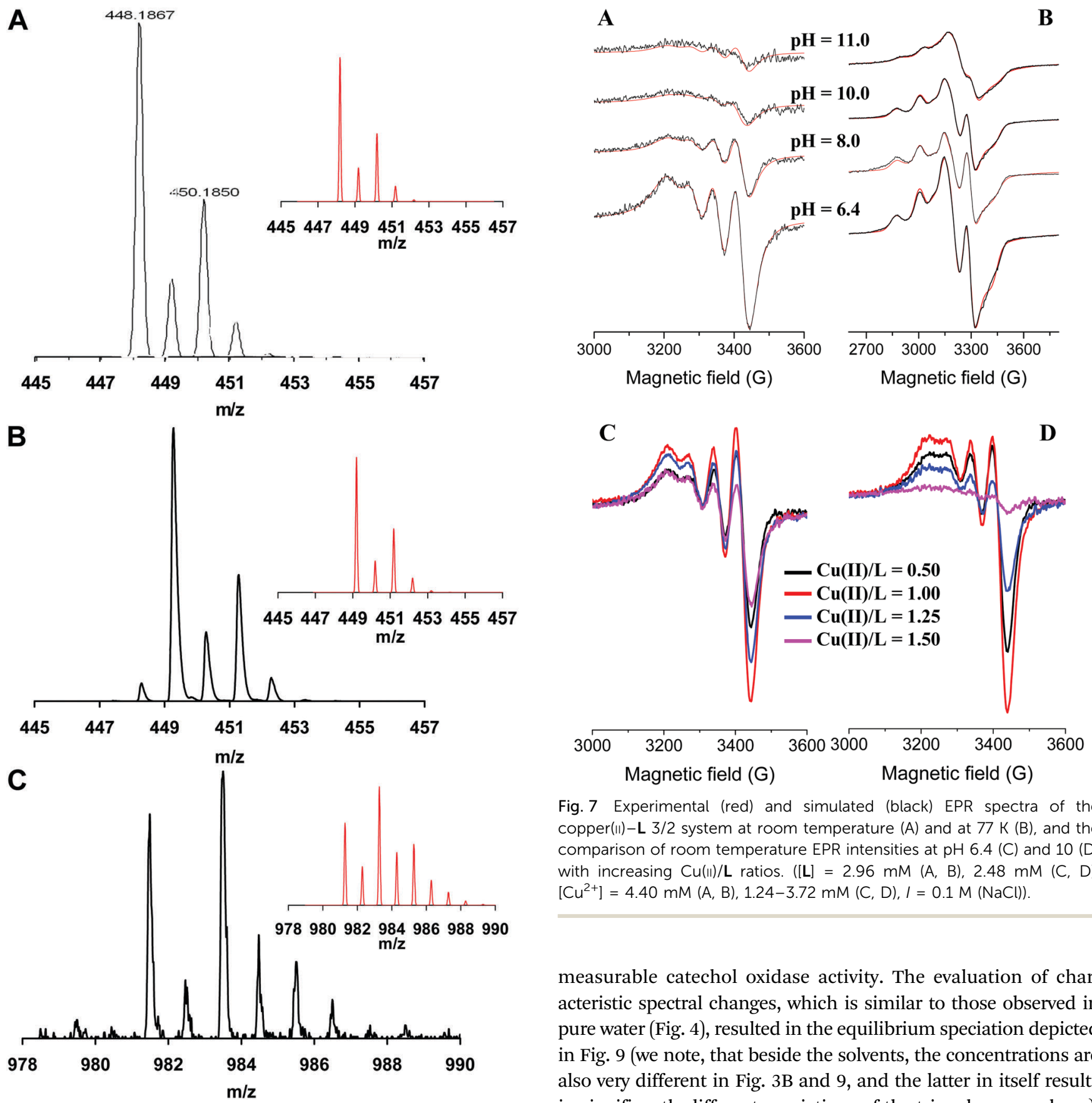

Fig. 7 Experimental (red) and simulated (black) EPR spectra of the copper(II) - L 3/2 system at room temperature (A) and at $77 \mathrm{~K}(\mathrm{~B})$, and the comparison of room temperature EPR intensities at $\mathrm{pH} 6.4$ (C) and 10 (D) with increasing $\mathrm{Cu}(\mathrm{II}) / \mathrm{L}$ ratios. $([\mathrm{L}]=2.96 \mathrm{mM}(\mathrm{A}, \mathrm{B}), 2.48 \mathrm{mM}(\mathrm{C}, \mathrm{D})$, $\left[\mathrm{Cu}^{2+}\right]=4.40 \mathrm{mM}(\mathrm{A}, \mathrm{B}), 1.24-3.72 \mathrm{mM}(\mathrm{C}, \mathrm{D}), I=0.1 \mathrm{M}(\mathrm{NaCl})$ ).

Fig. 6 ESI-MS (A), MALDI-TOF MS (B and $C$ ) spectrum detected for $\mathrm{CuH}_{-1} \mathrm{~L}\left(\mathrm{~A}\right.$ and $\mathrm{B}$ ) and $\mathrm{Cu}_{3} \mathrm{H}_{-4} \mathrm{~L}_{2}(\mathrm{C})$. Inserts show the calculated spectra for compositions [ $\left.\mathrm{CuN}_{10} \mathrm{C}_{18} \mathrm{H}_{29}\right]^{+}(\mathrm{A}),\left[\mathrm{CuN}_{10} \mathrm{C}_{18} \mathrm{H}_{30}\right]^{+}(\mathrm{B})$ and $\left[\mathrm{Cu}_{3} \mathrm{~N}_{20} \mathrm{C}_{36} \mathrm{H}_{57} \mathrm{Na}\right]^{+}$ respectively.

The formation of the product 3,5-di-tert-butyl-o-benzoquinone (dtbq) was followed spectrophotometrically at $400 \mathrm{~nm}$ in a $50 \% \mathrm{EtOH} / \mathrm{H}_{2} \mathrm{O}$ solvent, in order to enhance the solubility of dtbq. To obtain a detailed picture of the catalytic reaction, the speciation of copper(II) complexes should be known in a $50 \%$ $(\mathrm{m} / \mathrm{m})$ ethanol-water mixture. To this end, we studied the $\mathrm{pH}$ dependence of UV-Vis spectra of the $\mathrm{Cu}(\mathrm{II}) /$ trenpyz $3 / 2$ system (Fig. S7 and S8, ESI $\dagger$ ), since only trinuclear complexes show

measurable catechol oxidase activity. The evaluation of characteristic spectral changes, which is similar to those observed in pure water (Fig. 4), resulted in the equilibrium speciation depicted in Fig. 9 (we note, that beside the solvents, the concentrations are also very different in Fig. 3B and 9, and the latter in itself results in significantly different speciations of the trinuclear complexes). The formation of trinuclear complexes is shifted by $\sim 1$ unit to a lower $\mathrm{pH}$-range, as a consequence of the more favoured charge compensation in a $50 \%$ ethanol-water mixture.

The pH-rate constant profile of $\mathrm{H}_{2} \mathrm{dtbc}$ oxidation promoted by the trinuclear copper(II) complexes is a distorted bell-shaped curve with a pH optimum around $\mathrm{pH} 7.3$ (Fig. 9). This pH-rate constant profile is not directly comparable with the speciation of the binary complexes, since the oxidation of $\mathrm{H}_{2} \mathrm{dtbc}$ promoted by the copper(II) complexes requires the formation of a complex-dtbc ternary adduct, which is a pH-dependent process. Therefore, the strong metal ion binder $\mathrm{H}_{2} \mathrm{dtbc}$ obviously alters the complex speciation obtained in the binary system. Consequently, Fig. 9 shows that the observed catalytic activity is mainly related to 


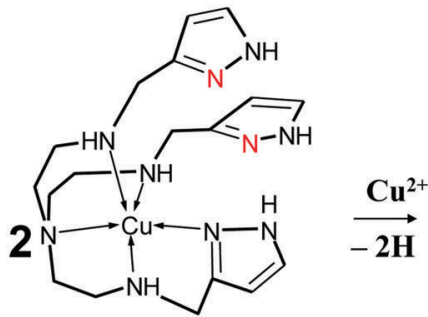

CuL

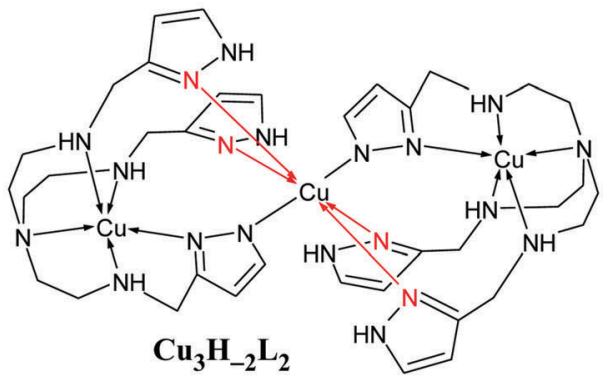<smiles>c1c[nH]c(CN2CCN(Cc3cc[nH]n3)C23CN(Cc2cc[nH]n2)CCN3Cc2cc[nH]n2)n1</smiles>

CuL

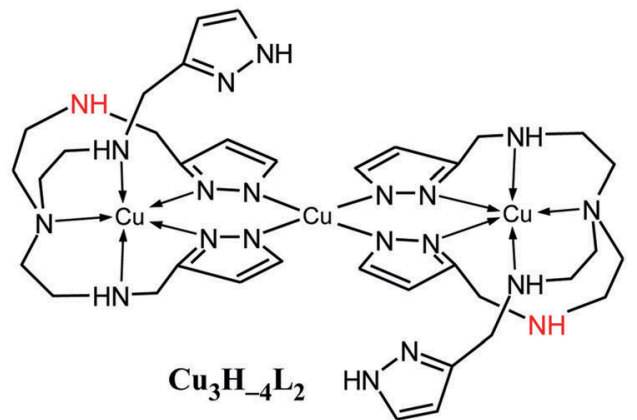

Scheme 2 Schematic structure of the formation of $\mathrm{Cu}_{3} \mathrm{H}_{-2} \mathrm{~L}_{2}$ and $\mathrm{Cu}_{3} \mathrm{H}_{-4} \mathrm{~L}_{2}$.

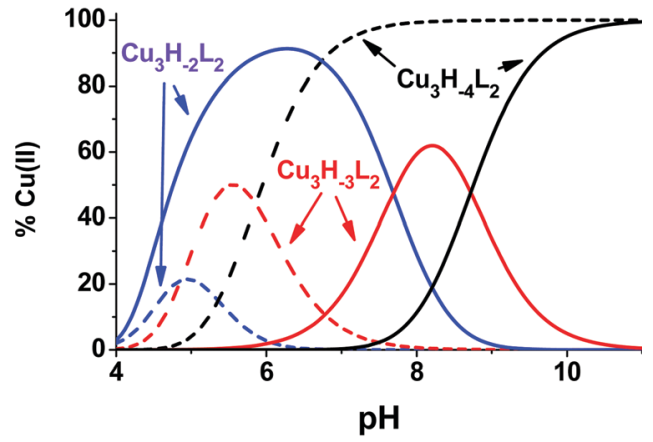

Fig. 8 Speciation of the trinuclear complexes in the $\mathrm{Cu}(I)$-tachpyz (dashed lines) and in the $\mathrm{Cu}(\mathrm{I})$-trenpyz (solid lines) $3 / 2$ systems $(T=298 \mathrm{~K}, I=0.1 \mathrm{M}$ $\left.\mathrm{NaCl},\left[\mathrm{Cu}^{2+}\right]_{\mathrm{tot}}=2.0 \mathrm{mM}\right)$.

the triply deprotonated $\mathrm{Cu}_{3} \mathrm{H}_{-3} \mathbf{L}_{2}$, similarly to the related $\mathrm{Cu}(\mathrm{II})$-tachpyz system. ${ }^{13}$

In order to obtain some additional information on the binding of the substrate $\mathrm{H}_{2} \mathrm{dtbc}$ to the trinuclear complexes, we studied their interaction with 4-nitrocatechol $\left(\mathrm{H}_{2} 4 \mathrm{nc}\right)$, as a stable chromophoric probe for catechol derivatives. ${ }^{55}$ The increasing amount of $\mathrm{H}_{2} 4$ nc added to the $\mathrm{Cu}$ (II)-trenpyz 3/2 system (Fig. 10) results in the development of an absorption peak at $440 \mathrm{~nm}$. Although the $\mathrm{p} K_{1}$ of 4-nitrocatechol under these conditions is $6.8 \pm 0.1,{ }^{41}$ i.e. unbound $\mathrm{H} 4 \mathrm{nc}^{-}$is also present $\left(\lambda_{\max }\right.$ at $\left.432 \mathrm{~nm}^{41}\right)$, the weak breakpoint at a $1 / 1\left[\mathrm{H}_{2} 4 \mathrm{nc}\right] /\left[\mathrm{Cu}_{3} \mathrm{H}_{-x} \mathbf{L}_{2}\right]_{\text {tot }}$ ratio (inset in Fig. 10) can be clearly seen. This allowed the calculation of the apparent association constant for the $\left[\left(\mathrm{Cu}_{3} \mathrm{H}_{-x} \mathbf{L}_{2}\right)(4 \mathrm{nc})\right]$ adduct $(x=2$ and 3$) \log K_{\mathrm{app}}=4.4 \pm 0.1$ (solid line in the inset of Fig. 10), which confirms the high coordinating ability of catechol derivatives to the tricopper(II) core.

The interaction of trinuclear complexes with $\mathrm{H}_{2} \mathrm{dtbc}$ was studied under anaerobic conditions too. The increasing concentration of

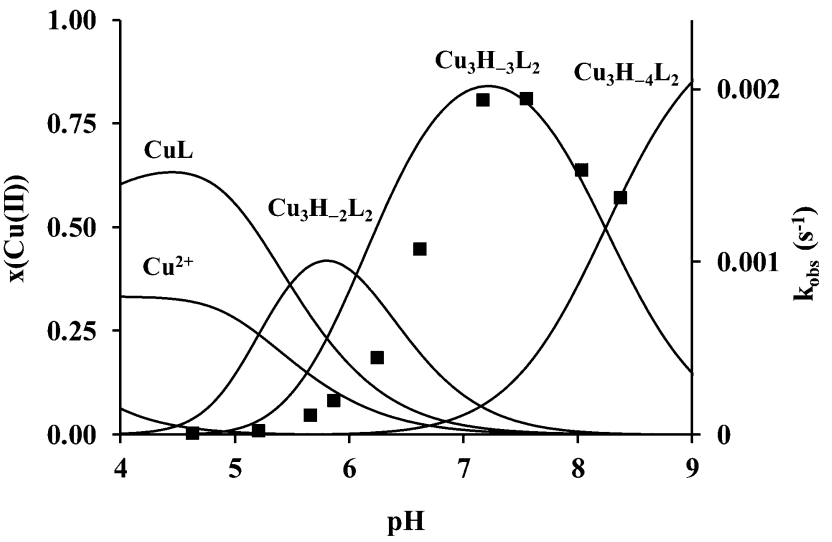

Fig. $9 \mathrm{pH}$-Rate constant profile of the oxidation of $\mathrm{H}_{2} \mathrm{dtbc}$ promoted by the copper(II) complexes in $50 \% \mathrm{EtOH}-\mathrm{H}_{2} \mathrm{O}$ (secondary axis) and the speciation diagrams of the copper-trenpyz $3 / 2$ system under the same conditions $\left(T=298 \mathrm{~K} ;\left[\mathrm{Cu}^{2+}\right]=75 \mu \mathrm{M} ;[\mathrm{L}]=50 \mu \mathrm{M} ;\left[\mathrm{H}_{2} \mathrm{dtbc}\right]_{0}=2 \mathrm{mM}\right)$.

$\mathrm{H}_{2} \mathrm{dtbc}$ results in partial, but immediate formation of dtbq (the absorption band at $400 \mathrm{~nm}$, Fig. S9, ESI $\dagger$ ), which approaches the [dtbq] $/\left[\mathrm{Cu}_{3} \mathrm{H}_{-x} \mathbf{L}_{2}\right]=1 / 1$ ratio above 20 -fold excess of $\mathrm{H}_{2} \mathrm{dtbc}$ over the trinuclear complexes. This observation is consistent with two-electron oxidation of the catechol substrate by the trinuclear species, which is the main proposed mechanism for oligonuclear catechol oxidase mimicking copper(II) complexes. ${ }^{43}$ However, this anaerobic reaction is not stoichiometric, in accordance with many previous studies where the formation of dtbq was complete only at considerable excess of $\mathrm{H}_{2} \mathrm{dtbc} .^{56,57}$

The direct electron transfer from the substrate to the trinuclear complex underlines the importance of the electrochemistry of the trinuclear complexes, which was studied by cyclic voltammetry in a $50 \%(\mathrm{~m} / \mathrm{m})$ ethanol-water solvent 


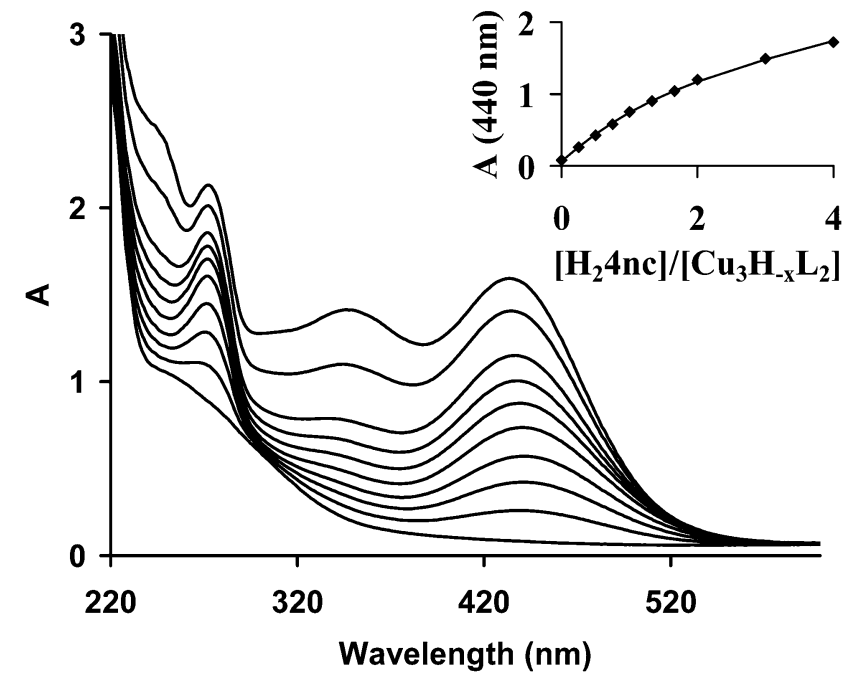

Fig. 10 UV-Vis spectra of the Cu(II)-trenpyz $3 / 2$ system in $50 \%$ ethanolwater as a function of increasing concentration of $\mathrm{H}_{2} 4 \mathrm{nc}$, the inset shows the change of absorbances at $440 \mathrm{~nm}$ as a function of $\left[\mathrm{H}_{2} 4 \mathrm{nc}\right] /\left[\mathrm{Cu}_{3} \mathrm{H}_{-x} \mathrm{~L}_{2}\right]$ ratio $\left(T=298 \mathrm{~K},\left[\mathrm{Cu}^{2+}\right]=0.17 \mathrm{mM},[\mathrm{L}]=0.12 \mathrm{mM}, \mathrm{pH}=7.2\right)$.

mixture at $\mathrm{pH} 7.3$ and at a $\mathrm{Cu}(\mathrm{II})$-trenpyz $3 / 2$ ratio (Fig. S10, ESI $\dagger)$. Only irreversible redox couples were observed. The relatively well-developed reduction peak at $E_{\mathrm{pc}}=0.4 \mathrm{~V}$ ( $v s$. NHE) indicates notable stabilization of copper(I), and can be tentatively assigned to the $\mathrm{Cu}^{\mathrm{II}} \mathrm{Cu}^{\mathrm{II}} \mathrm{Cu}^{\mathrm{II}} \rightarrow \mathrm{Cu}^{\mathrm{II}} \mathrm{Cu}^{\mathrm{I}} \mathrm{Cu}^{\mathrm{II}}$ process, which is followed by two subsequent irreversible reduction steps in the $E_{\mathrm{pc}}=0.0-(-0.4) \mathrm{V}$ range (Fig. S9, ESI $\dagger$ ).

At the optimal $\mathrm{pH}$, the initial rate of oxidation shows saturation kinetics above 100-fold excess of the substrate over the trinuclear complexes, according to the Michealis-Menten model. This also indicates the formation of the catalytically active $\mathrm{Cu}$ (II)-trenpyz-dtbc ternary complex in a fast pre-equilibrium, followed by the rate determining intramolecular redox processes. The non-linear regression of the kinetic data in Fig. 11 resulted in $k_{\text {cat }}=(0.156 \pm 0.005) \mathrm{s}^{-1}$ and $K_{\mathrm{M}}=(0.94 \pm 0.10) \mathrm{mM}$ (see solid line). These values are very similar to those obtained in the $\mathrm{Cu}(\mathrm{II})$-tachpyz system, ${ }^{13}$ although at different $\mathrm{pH}$ values.

The comparison with other catechol oxidase models is complicated by different conditions used (solvent, $\mathrm{pH}$ and temperature). Nevertheless, above data confirm the relatively strong substrate binding, as expected for oligonuclear complexes. Although the catalytic rate constant $\left(k_{\text {cat }}\right)$ is higher than most values reported earlier for dinuclear species, ${ }^{49,54,57,58}$ 10-60-fold more active complexes are also known in the literature. ${ }^{46,48,51}$

The reaction rates were also measured as a function of the concentration of trinuclear complexes and dioxygen, under pseudo-first order conditions (Fig. S11 and S12, ESI $\dagger$ ). In both cases first order dependence was observed. From the MichaelisMenten model it follows that the observed pseudo-second order rate constant $\left(k^{\prime}\right.$, the slope of the straight line in Fig. S10, ESI $\left.\dagger\right)$ is equal to $k_{\text {cat }} /\left(K_{\mathrm{M}}+[\mathrm{S}]\right)$. The value calculated from the MichaelisMenten parameters $\left(k_{\text {calc }}{ }^{\prime}=53.0 \mathrm{M}^{-1} \mathrm{~s}^{-1}\right)$ is in good agreement with the measured one $\left(k^{\prime}=72.3 \mathrm{M}^{-1} \mathrm{~s}^{-1}\right.$, Fig. S11, ESI $\left.\dagger\right)$, which confirms the accuracy of our kinetic data.



Fig. 11 The initial rate of $\mathrm{H}_{2} \mathrm{dtbc}$ oxidation catalyzed by the $\mathrm{Cu}(॥)$ - trenpyz $3 / 2$ system as a function of substrate concentration $(T=298 \mathrm{~K} ; \mathrm{pH}=7.2$; $\left.\left[\mathrm{Cu}^{2+}\right]=75 \mu \mathrm{M},[\mathrm{L}]=50 \mu \mathrm{M}\right)$.

In the interest of having more details on the mechanism of $\mathrm{H}_{2}$ dtbc oxidation, we measured the concentration of $\mathrm{H}_{2} \mathrm{O}_{2}$ formed during the oxidation promoted by the trinuclear complexes in parallel with that of dtbq (Fig. S13, ESI $\dagger$ ). $\mathrm{H}_{2} \mathrm{O}_{2}$ was produced in nearly stoichiometric quantities compared to dtbq, implying that it does not participate in the catalytic reaction.

According to the two-electron oxidation of the substrate, suggested by our anaerobic measurements (see above), the formation of radicals (e.g. semiquinone) was not observed on the EPR spectra obtained during the catalytic process under aerobic conditions (Fig. S14, ESI $\dagger$ ). Instead, the intensity of the EPR spectra decreased after addition of the substrate, and the low temperature spectra showed also some shifts by time (Fig. S14B, ESI $\dagger$ ). These observations are in agreement with the partial formation of the complex-substrate adduct and/or the mixed-valence tricopper species. In this respect it is worth noting that due to the concentration of the trinuclear species required for EPR measurements, our system was far from the saturating conditions observed in Fig. 11.

The above kinetic data can be interpreted by a simplified variant of the mechanism originally proposed by Casella et al. ${ }^{50}$ (Scheme 3): the complex $\mathrm{Cu}_{3} \mathrm{H}_{-3} \mathbf{L}_{2}$ forms a stable ternary complex with $\mathrm{H}_{2} \mathrm{dtbc}$ in a fast pre-equilibrium, and an intramolecular two-electron transfer process results in the formation of dtbq and two copper(I) centres. Upon product dissociation, the copper(I) centres are re-oxidized by dioxygen producing the tricopper(II) complex and $\mathrm{H}_{2} \mathrm{O}_{2}$.

Since the peripheral copper(II) ions in the trinuclear complexes have a similar trigonal bipyramidal geometry to the inactive mononuclear species, the pyrazolate-bound central copper(II) ion should have the governing role in the binding and oxidation of $\mathrm{H}_{2} \mathrm{dtbc}$.

The catalytic properties of the trinuclear $\mathrm{Cu}(\mathrm{II})$-trenpyz and $\mathrm{Cu}(\mathrm{II})$-tachpyz ${ }^{13}$ complexes are worth comparing. The two systems possess a number of similar properties: (i) the triply deprotonated trinuclear complexes are the active species, (ii) their catalytic 


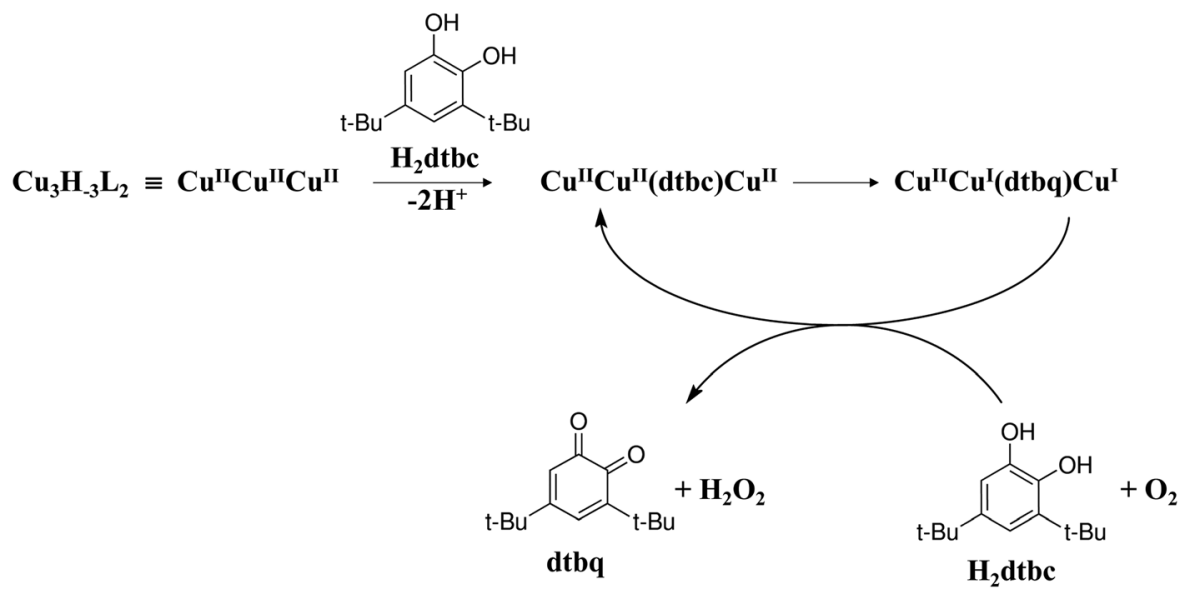

Scheme 3 Proposed mechanism for catalytic oxidation of 3,5-di-tert-butylcatechol by the trenpyz-copper(॥) 3/2 system.



Fig. $12 \mathrm{pH}$-pseudo-second order rate constant profile of dtbc oxidation in $50 \mathrm{w} \%$ ethanol-water promoted by the copper(॥)-tachpyz ${ }^{13}$ (open square) and -trenpyz (filled square) $3 / 2$ systems at $T=298 \mathrm{~K}$.

efficiencies are nearly identical, and (iii) the central copper(II) ions have a major role in the oxidation of the substrate, (iv) which proceeds by intramolecular two-electron transfer. Only the pH-rate constant profiles show notable differences, the pH-optimum of the present system is shifted by $\sim$ two units to the higher pH (Fig. 12). This is due to the different speciations of the trinuclear complexes in the two systems (Fig. 8), which in turn resultsin the different tripodal platforms used. All these facts imply that the dtbc oxidation promoted by these systems can be easily controlled by the denticity of the tripodal ligands, since it affects the coordination environment of the central metal ion, which is proposed to be the main actor during the reaction.

\section{Conclusion}

We prepared the pyrazole-containing oligonucleating tripodal ligand trenpyz (L) and studied the equilibrium, structural and chatecolase properties of its copper(II) complexes. In equimolar solution the highly stable square pyramidal CuHL and trigonal bipyramidal CuL are the dominant species around $\mathrm{pH} 3$ and 5-8, respectively. Above $\mathrm{pH} 8$ further deprotonation was observed ( $\mathrm{p} K=9.56$ ), which is related to the formation of a copper(II)bound pyrazolate anion. This creates the possibility for the formation of oligonuclear complexes, through pyrazolate bridges, and at a $3 / 2 \mathrm{Cu}(\mathrm{II}) / \mathbf{L}$ ratio three trinuclear complexes were identified. The species $\mathrm{Cu}_{3} \mathrm{H}_{-2} \mathbf{L}_{2}$ is significantly stabilized, $\mathrm{Cu}_{3} \mathrm{H}_{-3} \mathbf{L}_{2}$ and $\mathrm{Cu}_{3} \mathrm{H}_{-4} \mathbf{L}_{2}$ are destabilized as compared to the analogous $\mathrm{Cu}_{3} \mathrm{H}_{-x}$ (tachpyz $)_{2}$ complexes due to the different denticities of the two ligands, which results in considerably different speciations of the trinuclear complexes. At the optimal $\mathrm{pH}$ the catechol oxidase activities of the triply deprotonated trinuclear complexes of trenpyz and tachpyz are similar, but their pH-rate constant profiles are significantly different, as a consequence of the above mentioned deviations in the complex speciation. Our work pointed out that by derivatization of some simple tripodal platforms (tren, tach) it is possible to fine-tune the coordination chemical properties such as structure and stability, and even some important enzyme like features, such as the $\mathrm{pH}$-activity profile.

\section{Conflicts of interest}

There are no conflicts to declare.

\section{Acknowledgements}

The research was supported by National Research, Development and Innovation Office (NKFIH) through projects GINOP2.3.2-15-2016-00038, OTKA 101541 and OTKA 115762. The authors warmly thank F. Lachaud for MS measurements at Université de Lorraine.

\section{References}

1 A. G. Blackman, Polyhedron, 2005, 24, 1.

2 G. Parkin, Chem. Rev., 2004, 104, 699-767. 
3 B. Kuswandi, Nuriman, W. Verboom and D. N. Reinhoudt, Sensors, 2006, 6, 978-1017.

4 A. Deroche, I. Morgenstern-Badarau, M. Cesario, J. Guilhem, B. Keita, L. Nadjo and C. Houée-Levin, J. Am. Chem. Soc., 1996, 118, 4567-4573.

5 T. J. Wadas, E. H. Wong, G. R. Weisman and C. J. Anderson, Chem. Rev., 2010, 110, 2858-2902.

6 J. Turner, C. Koumenis, T. E. Kute, R. P. Planalp, M. W. Brechbiel, D. Beardsley, B. Cody, K. D. Brown, F. M. Torti and S. V. Torti, Blood, 2005, 106, 3191-3199.

7 A. Mohamadou and C. Gérard, J. Chem. Soc., Dalton Trans., 2001, 3320-3328.

8 G. Park, E. Dadachova, A. Przyborowska, S.-J. Lai, D. Ma, G. Broker, R. Rogers, R. Planalp and M. Brechbiel, Polyhedron, 2001, 20, 3155-3163.

9 C. Gérard, A. Mohamadou, J. Marrot, S. Brandes and A. Tabard, Helv. Chim. Acta, 2005, 88, 2397-2412.

10 S.-F. Tong, H. Yang, Y.-N. Lao, G.-H. Liu, H.-X. Wu, S.-P. Yang, J. Yu, H. Tan and W. Li, Z. Anorg. Allg. Chem., 2009, 635, 2340-2346.

11 S. R. Bayly, Z. Xu, B. O. Patrick, S. J. Rettig, M. Pink, R. C. Thompson and C. Orvig, Inorg. Chem., 2003, 42, 1576-1583.

12 A. Mustapha, C. Busche, J. Reglinski and A. R. Kennedy, Polyhedron, 2011, 30, 1530-1537.

13 A. Szorcsik, F. Matyuska, A. Bényei, N. V. Nagy, R. K. Szilágyi and T. Gajda, Dalton Trans., 2016, 45, 14998-15012.

14 J. Klingele, S. Dechert and F. Meyer, Coord. Chem. Rev., 2009, 253, 2698.

15 K. E. Dalle and F. Meyer, Eur. J. Inorg. Chem., 2015, 3391.

16 A. Prokofieva, A. I. Prikhod'ko, E. A. Enyedy, E. Farkas, W. Maringgele, S. Demeshko, S. Dechert and F. Meyer, Inorg. Chem., 2007, 46, 4298.

17 J. Ackermann, F. Meyer, E. Kaifer and H. Pritzkow, Chem. - Eur. J., 2002, 8, 247.

18 J. Ackermann, S. Buchler and F. Meyer, C. R. Chim., 2007, 10, 421.

19 T. Higashi, NUMABS, Rigaku/MSC Inc., 1998, rev. 2002.

20 CrystalClear SM 1.4.0, Rigaku/MSC Inc., 2008.

21 M. C. Burla, R. Caliandro, B. Carrozzini, G. L. Cascarano, C. Cuocci, C. Giacovazzo, M. Mallamo, A. Mazzone and G. Polidori, J. Appl. Crystallogr., 2015, 48, 306-309.

22 SHELXL-2013 Program for Crystal Structure Solution, University of Göttingen, Germany, 2013.

23 L. J. Farrugia, J. Appl. Crystallogr., 2012, 45, 849-854.

24 A. L. Spek, J. Appl. Crystallogr., 2003, 36, 7-13.

25 C. F. Macrae, P. R. Edgington, P. McCabe, E. Pidcock, G. P. Shields, R. Taylor, M. Towler and J. van De Streek, J. Appl. Crystallogr., 2006, 39, 453-457.

26 S. P. Westrip, J. Appl. Crystallogr., 2010, 43, 920-925.

27 F. J. C. Rosotti and H. Rosotti, The determination of stability constants, McGraw-Hill Book Co., New York, 1962, p. 149.

28 E. Högfeldt, Stability Constants of Metal-Ion Complexes, Part A. Inorganic Ligands, Pergamon, New York, 1982, p. 32.

29 L. Z. I. N. G. Peintler, Technical Software Distributors, Baltimore, MD, 1991.
30 R. G. Bates, M. Paabo and R. A. Robinson, J. Phys. Chem., 1963, 67, 1833-1838.

31 L. G. Hepler, E. M. Woolley and D. G. Hurkot, J. Phys. Chem., 1970, 74, 3908-3913.

32 A. J. Bard and L. R. Faulkner, Electrochemical MethodsFundamentals and Applications, John Wiley \& Sons, New York, 2000.

33 A. Rockenbauer and L. Korecz, Appl. Magn. Reson., 1996, 10, 29-43.

34 A. W. Addison, T. Nageswara Rao, J. Reedijk, J. van Rijn and G. C. Verschoor, J. Chem. Soc., Dalton Trans., 1984, 1349-1356.

35 G. Brewer, C. T. Brewer, R. J. Butcher and E. E. Carpenter, Inorg. Chim. Acta, 2006, 359, 1263.

36 R. J. Motekaitis, A. E. Martell, J. M. Lehn and E. I. Watanabe, Inorg. Chem., 1982, 21, 4253-4257.

37 L. Chruscinski, P. Mlynarz, K. Malinowska, J. Ochocki, B. Boduszek and H. Kozlowski, Inorg. Chim. Acta, 2000, 303, 47-53.

38 P. Lubal, M. Kývala, P. Hermann, J. Holubová, J. Rohovec, J. Havel and I. Lukes, Polyhedron, 2001, 20, 47-55.

39 G. Greiner, L. Seyfarth, W. Poppitz, R. Witter, U. Sternberg and S. Reissmann, Lett. Pept. Sci., 2000, 7, 133-141.

40 K. Ösz, K. Várnagy, H. Süli-Vargha, D. Sanna, G. Micera and I. Sóvágó, J. Chem. Soc., Dalton Trans., 2003, 2009-2016.

41 A. Dancs, N. V. May, K. Selmeczi, Z. Darula, A. Szorcsik, F. Matyuska, T. Páli and T. Gajda, New J. Chem., 2017, 41, 808-823.

42 J. Sanmartín, M. R. Bermejo, A. M. García-Deibe, O. R. Nascimento, L. Lezama and T. Rojo, J. Chem. Soc., Dalton Trans., 2002, 1030-1035; I. P.-C. Liu, P. P.-Y. Chen and S. I. Chan, C. R. Chim., 2012, 15, 214-224.

43 I. A. Koval, P. Gamez, C. Belle, K. Selmeczi and J. Reedijk, Chem. Soc. Rev., 2006, 35, 814.

44 T. Klabunde, C. Eicken, J. C. Sachettini and B. Krebs, Nat. Struct. Biol., 1998, 5, 1084-1090.

45 N. Hakulinen, C. Gasparetti, H. Kaljunen, K. Kruus and J. Rouvinen, JBIC, J. Biol. Inorg. Chem., 2013, 18, 917.

46 K. S. Banu, T. Chattopadhyay, A. Banerjee, S. Bhattacharya, E. Suresh, M. Nethaji, E. Zangrando and D. Das, Inorg. Chem., 2008, 47, 7083-7093.

47 I. A. Koval, K. Selmeczi, C. Belle, C. Philouze, E. Saint-Aman, I. Gautier-Luneau, A. M. Schuitema, M. van Vliet, P. Gamez, O. Roubeau, M. Lueken, B. Krebs, M. Lutz, A. L. Spek, J.-L. Pierre and J. Reedijk, Chem. - Eur. J., 2006, 12, 6138-6150.

48 J. Ackermann, S. Buchler and F. Meyer, C. R. Chim., 2007, 10, 421-432.

49 A. Neves, L. M. Rossi, A. J. Bortoluzzi, B. Szpoganicz, C. Wiezbicki, E. Schwingel, W. Haase and S. Ostrovsky, Inorg. Chem., 2002, 41, 1788-1794.

50 E. Monzani, L. Quinti, A. Perotti, L. Casella, M. Gullotti, L. Randaccio, S. Geremia, G. Nardin, P. Faleschini and G. Tabbi, Inorg. Chem., 1998, 37, 553-562.

51 E. C. M. Ording-Wenker, M. A. Siegler, M. Lutz and E. Bouwman, Dalton Trans., 2015, 44, 12196-12209. 
52 A. Jancsó, Z. Paksi, N. Jakab, B. Gyurcsik, A. Rockenbauer and T. Gajda, Dalton Trans., 2005, 3187-3194.

53 J. Kaizer, T. Csay, G. Speier and M. Giorgi, J. Mol. Catal. A: Chem., 2010, 329, 71-76.

54 L. K. Das, A. Biswas, J. S. Kinyon, N. S. Dalal, H. Zhou and A. Ghosh, Inorg. Chem., 2013, 52, 11744.

55 C. A. Tyson, J. Biol. Chem., 1975, 250, 1765.
56 A. Granata, E. Monzani and L. Casella, JBIC, J. Biol. Inorg. Chem., 2004, 9, 903-913.

57 E. Monzani, L. Casella, G. Zoppellaro, M. Gullotti, R. Pagliarin, R. P. Bonomo, G. Tabbi, G. Nardin and L. Randaccio, Inorg. Chim. Acta, 1998, 282, 180-192.

58 S. J. Smith, C. J. Noble, R. C. Palmer, G. R. Hanson, G. Schenk, L. R. Gahan and M. J. Riley, J. Biol. Inorg. Chem., 2008, 13, 499-510. 